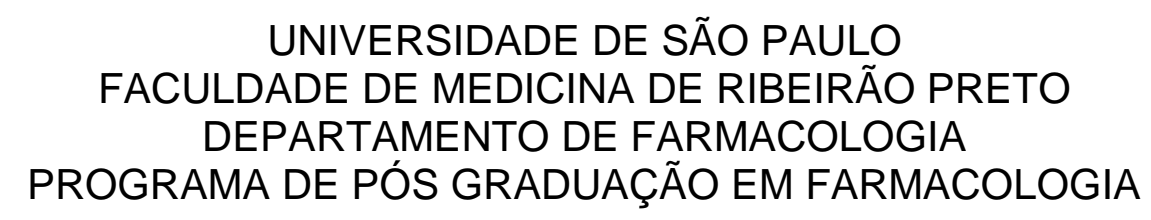

ATLANTE SILVA MENDES

VERAPAMIL DIMINUI A EXPRESSÃO PROTEICA DE CALPAÍNA-1 E METALOPROTEINASE DE MATRIZ-2 NA HIPERTROFIA CARDÍACA INDUZIDA POR HIPERTENSÃO RENOVASCULAR 


\title{
VERAPAMIL DIMINUI A EXPRESSÃO PROTEICA DE CALPAÍNA-1 E METALOPROTEINASE DE MATRIZ-2 NA HIPERTROFIA CARDÍACA INDUZIDA POR HIPERTENSÃO RENOVASCULAR
}

\begin{abstract}
Dissertação de mestrado apresentada ao Programa de Pós-graduação em Farmacologia da Faculdade de Medicina de Ribeirão Preto da Universidade de São Paulo para a obtenção do título de Mestre em Ciências.
\end{abstract}

Área de Concentração: Farmacologia

Orientadora: Prof ${ }^{a}$. Dr ${ }^{\mathrm{a}}$ Michele Mazzaron de Castro 


\section{FOLHA DE APROVAÇÃO}

Autor: Atlante Silva Mendes

Título: VERAPAMIL DIMINUI A EXPRESSÃO PROTEICA DE CALPAÍNA-1 E METALOPROTEINASE DE MATRIZ-2 NA HIPERTROFIA CARDÍACA INDUZIDA POR HIPERTENSÃO RENOVASCULAR

Dissertação de mestrado apresentada ao Programa de Pós-graduação em Farmacologia da Faculdade de Medicina de Ribeirão Preto da Universidade de São Paulo para a obtenção do título de Mestre em Ciências.

Área de Concentração: Farmacologia

Aprovado em:

BANCA EXAMINADORA

Prof:

Instituição:

Assinatura:

Prof:

Instituição:

Assinatura:

Prof:

Instituição:

Assinatura: 
AUTORIZO A DIVULGAÇÃO TOTAL OU PARCIAL DESTE TRABALHO POR QUALQUER MEIO CONVENCIONAL OU ELETRÔNICO, PARA FINS DE ESTUDO E PESQUISA, DESDE QUE CITADO A FONTE.

\section{FICHA CATALOGRÁFICA}

Mendes, Atlante Silva

Verapamil diminui a expressão proteica de calpaína-1 e metaloproteinase de matriz-2 na hipertrofia cardíaca induzida por hipertensão renovascular/ Atlante Silva Mendes; Orientadora: Prof $^{a}{ }^{a} r^{a}$ Michele Mazzaron de Castro. Ribeirão Preto, 2018.

62 folhas.

Dissertação (Mestrado em Ciências - Programa de Pós-graduação em Farmacologia. Área de concentração: Farmacologia) - Faculdade de Medicina de Ribeirão Preto, Universidade de São Paulo, 2018.

1. Hipertrofia cardíaca, 2. Hipertensão renovascular, 3. Calpaína-1, 4. MMP2, 5. Verapamil. 
À minha família.

À de sangue. Às de vida. 


\section{AGRADECIMENTOS}

À minha família pelo apoio, pelo reconhecimento, pela luta, pelo carinho, pela história de cada um de vocês. Morar distante me priva de momentos ao seu lado e me fazem questionar escolhas e tomar decisões. Tudo que tenho devo a vocês. Por tudo que consegui os agradeço.

À um dos meus melhores amigos, Mouzarllem Barros dos Reis, por nossa ligação de 7 anos, pelo incentivo para a vinda pra Ribeirão Preto, pois de fato pude crescer e aprender inúmeras lições importantíssimas para a consolidação da minha personalidade. Foi alguém imprescindível para a tomada de decisões muito importantes. E continuará sendo.

A outro dos meus melhores amigos, Jeimison Duarte, pelo incentivo para a vinda pra Ribeirão Preto, pelos conselhos profissionais e de vida, pelos dias de risada durante o trabalho e fora dele, sobretudo, por ser paciente comigo. Você bem sabe o porquê.

A uma pessoa que tem sido muito importante para mim nos dias atuais e com quem eu decidi compartilhar toda e qualquer parte da minha vida. Augusto Veloso, você tem sido muito especial para mim e com você tenho aprendido lições que nenhum dos meus melhores amigos é capaz de me ensinar. Agradeço muito por você está ao meu lado e por fazer parte da sua vida.

Ao laboratório, eu agradeço pela oportunidade de crescimento e aprendizado. À prof ${ }^{a}$ Michele Mazzaron, pela paciência, pelos ensinamentos profissionais e pelo conhecimento. Juliana Montenegro Parente e Eliane Maciel pelos dois mais 
maravilhosos anos da minha vida profissional. Com vocês pude ser feliz mesmo nos momentos difíceis, pude aprender a tentar ser organizado (ainda não consegui por completo ahahaha). Agradeço pelo carinho que vocês têm por mim (mesmo que eu mereça umas correções de vez em quando), pelos momentos de confraternização, pelos conselhos, pelos cafés.... Nossa, muita coisa para agradecer pra vocês. Marcela Blascke, pelo seu carisma. Esse laboratório não é o mesmo sem você. Pedro e Marília, obrigado pelo companheirismo. Espero que tenha contribuído de alguma forma para o crescimento de vocês dentro do laboratório. Aprendi muito com todos. Às entidades de fomento, o agradecimento pelo financiamento.

Agradeço pela contribuição dos diferentes colaboradores, que tornaram possível a execução das mais diferentes etapas do projeto, Evandro Manoel, Profo José Eduardo Tanus Santos, Ana Carolina Omoto, Vanessa Nakagi, Profo Rubens Fazan. Também gostaria de agradecer à Secretaria do Programa de Farmacologia por todo a ajuda durante os momentos difíceis, pelo companheirismo e conselhos. Gislaine e Ramon meu muito obrigado.

À toda a grande turma de Ribeirão Preto, Franciele, Vinicius, por tudo que passamos juntos desde o curso de inverno até hoje, momentos felizes, momentos de confraternização, momentos de tristeza, conversas construtivas. Ivaldo, Taiz, Jessica, Alice, Nicole, Melissa, Eduardo, Bruno Serpellone Naielly, Rafael, Stéfano, Wanessa, Teophanes, Cassiano, Mayara, Aline Fedoce, Andreza, Douglas, todas vocês são importantes para mim e me ajudam em todos os campos da minha vida aqui em Ribeirão Preto. 
À minha maravilhosa família que nasceu em Parnaíba, Paloma, Jayne, Gláucia, Lucian, Waldenrique, Isaac, Ana Carolina, Lhuana, Augusto, Isis, Renan, Kássio. Agradeço a vocês todos os dias, morro de saudades de vocês todos e desejo que todos vocês cresçam e se tornem aqueles profissionais que nós imaginávamos ser naqueles tempos onde tudo era mar e rosas.

À todas as outras pessoas não mencionadas que passaram por minha vida, meu muito obrigado. Tenham certeza que todos vocês deixaram seu pedacinho em mim.

Um grande e quente abraço a todos vocês. 
"A verdade é que a vida não é feita por quanto você respirou. É feita por quantas vezes você ficou sem fôlego". 


\section{RESUMO}

Título: Verapamil diminui a expressão proteica de calpaína-1 e metaloproteinase de matriz-2 na hipertrofia cardíaca induzida por hipertensão renovascular.

Introdução: A hipertrofia cardíaca induzida por sobrecarga hemodinâmica crônica (HC) é caracterizada por espessamento das paredes do ventrículo esquerdo e do tecido intersticial. As atividades aumentadas de calpaína-1 e metaloproteinase de matriz(MMP)-2 são observadas em diferentes modelos de hipertensão arterial e estão relacionadas com as mudanças fisiopatológicas na HC. Por outro lado, a atividade de MMP-2 parece ser modulada positivamente por ativação de calpaína-1 em diferentes modelos. O objetivo deste trabalho é analizar se a calpaína-1 contribui para o aumento da atividade de MMP-2 no coração e se esse mecanismo resulta nas mudanças crônicas cardíacas na hipertensão renovascular. Métodos: Ratos Wistar submetidos ao modelo de 2-rins-1 clipe (2R-1C)(180-200g) e seus respectivos controles (Sham) foram tratados com verapamil (VRP), um bloqueador de canais para cálcio tipo $\mathrm{L}(\mathrm{BCCL}, 8 \mathrm{mg} / \mathrm{kg} / \mathrm{bid}$ ) ou veículo durante 8 semanas. O BCCL reduz as concentrações intracelulares de cálcio, o que leva à diminuição da ativação de calpaína-1, e então à possível modulação da atividade e expressão proteica de MMP-2. Pressão arterial sistólica (PAS) dos ratos foi monitorada durante 10 semanas de hipertensão por pletismografia de cauda. $O$ ventrículo esquerdo (VE) foi analisado por histologia e ecocardiografia para avaliação das dimensões ventriculares. A atividade de calpaína-1 e MMP-2 foi avaliada por zimografia em gel. A expessão proteica de calpaína-1 e MMP-2 foi avaliada por western blot e imunofluorescência. Os corações foram submetidos à avaliação funcional por Langendorff. Todos os protocolos foram aprovados pelo Comitê de Ética em Pesquisa Animal da Faculdade de Medicina de Ribeirão Preto (43/2017). Resultados: Após 10 semanas, a PAS teve um aumento sustentado nos animais $2 \mathrm{R}-1 \mathrm{C}$ e o tratamento com VRP não foi capaz de reduzí-la em nenhum tempo de hipertensão. O peso corporal não apresentou diferença significativa entre os grupos. O grupo hipertenso teve um aumento da massa cardíaca quando comparado ao sham e o tratamento com verapamil reduziu esse parâmetro. A análise da espessura do ventrículo esquerdo demonstra que o VRP é capaz de reverter a $\mathrm{HC}$ induzida por sobrecarga pressórica nos animais hipertensos. Os animais 2R-1C apresentaram um aumento singificativo na expressão proteica e atividade de calpaína-1 e o VRP foi capaz de diminuir esses níveis. Foi observado aumento da atividade das isoformas de MMP-2 nos ratos $2 \mathrm{R}-1 \mathrm{C}$ quando comparados aos controles e o VRP foi capaz de reduzir a atividade da isoforma de $64 \mathrm{kDa}$. A contratilidade cardíaca intrínseca dos animais $2 \mathrm{R}-1 \mathrm{C}$ sugere uma disfunção cardíaca quando comparados aos controles sham, embora a fração de ejeção desses animais esteja preservada. O VRP não foi capaz de alterar esses parâmetros. Conclusão: O VRP pode contribuir para a redução da hipertrofia cardíaca por diminuir a expressão proteica de calpaína-1 e MMP-2 na hipertensão renovascular. Apoio financeiro: Capes, CNPq, FAPESP.

Palavras-chave: Hipertrofia cardíaca, hipertensão renovascular, Calpaína-1, MMP-2, Verapamil 


\begin{abstract}
Título: Verapamil decreases calpain-1 and matrix metalloproteinase-2 levels in renovascular hypertension-induced cardiac hypertrophy.

Introduction: The chronic hemodynamic overload-induced cardiac hypertrophy $(\mathrm{CH})$ is characterized by thickening of the left ventricle walls and hypertrophy of the cardiomyocytes and interstitial tissue. Increased activity of calpain-1 and matrix metalloproteinase(MMP)-2 was observed in different models of arterial hypertension models and contributes to the pathophysiologic changes shown in $\mathrm{CH}$. On the other hand, MMP-2 activity is also positively modulated by activation of calpain-1 in different animal models of cardiovascular diseases. The objectives here are to analyze whether calpain-1 contributes to increase the activity of MMP-2 in the heart and whether this mechanism results in chronic cardiac changes in the renovascular hypertension. Methods: Two kidney-one clip (2K1C) hypertensive male Wistar rats (180-200g) and their respective controls (Sham) were orally treated with verapamil (VRP), a L-type calcium channels blocker (LCCB, $8 \mathrm{mg} / \mathrm{kg} / \mathrm{bid}$ ), or vehicle during 8 weeks. The LCCB reduces the intracellular concentration of calcium, thus decreasing the activation of calpain-1, and then may modulate the activity of MMP-2. Systolic blood pressure (SBP) was monitored in the rats during 10 weeks of hypertension. Left ventricle (LV) was analyzed by histology and echocardiography to evaluate ventricle thickening. Calpain1 and MMP-2 activities were analyzed by zymography and their expression by immunofluorescence and western blot. Hearts were submitted to functional evaluation by Langendorff. All the protocols were approved by the Ethical Committee in Animal Research of Ribeirao Preto Medical School (43/2017). Results: After 10 weeks, the systolic blood pressure had sustained increase and treatment with VRP was not able to decrease it in any time of hypertension. The body weight did not present significant changes between the groups. Hypertensive group had significant increase in the ventricle/body weight ratio (VW/BW) when compared to sham and treatment with VRP decreased it. Analysis of ventricle thickening showed that VRP is able to revert $\mathrm{CH}$ induced pressure overload. The $2 \mathrm{~K}-1 \mathrm{C}$ rats showed a significant increase in the activity and expression of calpain-1 in the heart and VRP reverted it. It was also observed increased activity of MMP-2 forms in the hypertensive rats and VRP decreased the $64 \mathrm{kDa}$ MMP-2 activity. The $2 \mathrm{~K}-1 \mathrm{C}$ group had cardiac dysfunction when compared to controls groups, and VRP did not alter it. The ejection fraction was not changed in $2 \mathrm{~K}$ $1 \mathrm{C}$ rats. Conclusion: VRP decreased expression and activity of calpain-1 and MMP-2 in the hearts of $2 \mathrm{~K}-1 \mathrm{C}$ rats and then contributed to ameliorate hypertension-induced cardiac hypertrophy.
\end{abstract}

Palavras-chave: Cardiac hypertrophy, Renovascular hypertension, Calpain-1, MMP2, Verapamil 


\section{LISTA DE FIGURAS}

Figura 1: Representação esquemática dos efeitos do aumento da atividade de MMP2 nos cardiomiócitos. .21

Figura 2: Representação esquemática das vias de sinalização envolvidas na hipertrofia cardíaca dependente de calpaínas. .24

Figura 3: Avaliação da pressão arterial sistólica (A) e do peso corporal (B) dos animais ao longo das dez semanas de hipertensão renovascular e tratamento com cloridrato de verapamil $(8 \mathrm{mg} / \mathrm{kg} / \mathrm{bid})$ por gavagem

Figura 4: Expressão proteica de calpaína-1 por Western blot (A) e por imunofluorescência $(C)$ e avaliação da atividade caseinolítica por zimografia em gel das isoformas de calpaína (B) no ventrículo esquerdo dos animais submetidos à hipertensão renovascular por dez semanas e tratamento com cloridrato de verapamil $(8 \mathrm{mg} / \mathrm{kg} /$ bid) por gavagem

Figura 5: Avaliação da atividade gelatinolítica por zimografia em gel das isoformas de MMP-2 (A) e expressão proteica de MMP-2 por imunofluorescência (B) no ventrículo esquerdo dos animais submetidos à hipertensão renovascular por dez semanas e tratamento com cloridrato de verapamil $(8 \mathrm{mg} / \mathrm{kg} /$ bid $)$ por gavagem 
Figura 6: Avaliação morfológica por histologia corada com hematoxilina-eosina dos corações dos animais submetidos à hipertensão renovascular por dez semanas e tratamento com cloridrato de verapamil $(8 \mathrm{mg} / \mathrm{kg} /$ bid $)$ por

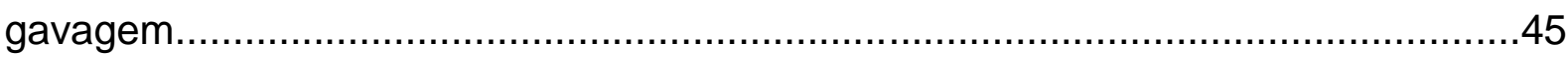

Figura 7: Avaliação morfológica por ecocardiograma dos corações dos animais submetidos à hipertensão renovascular por dez semanas e tratamento com cloridrato de verapamil $(8 \mathrm{mg} / \mathrm{kg} / \mathrm{bid})$ por gavagem .46

Figura 8: Avaliação da função cardíaca in vivo por ecodopplercardiografia (A) e ex vivo pela metodologia de Langendorff (B) dos animais submetidos ao protocolo de hipertensão renovascular por dez semanas, tratamento com cloridrato de verapamil $(8 \mathrm{mg} / \mathrm{kg} / \mathrm{bid})$ por gavagem e respectivos controles .49 


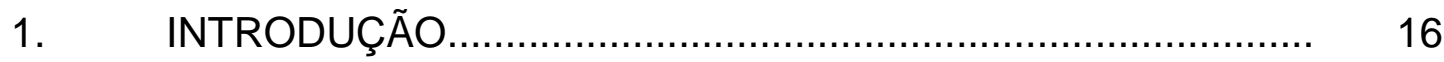

1.1. Hipertrofia cardíaca na hipertensão arterial........................... 16

1.2. As ações das MMPs na hipertrofia cardíaca da hipertensão arterial.

1.3. Sistema calpaína/calpastatina na hipertrofia cardíaca na hipertensão arterial

1.4. Regulação da MMP-2 pela calpaína-1 …................................ 26

2. JUSTIFICATIVA ....................................................... 29

3. OBJETIVO GERAL ........................................................ 30

3.1. Objetivos específicos..................................................... 30

4. MATERIAIS E MÉTODOS ............................................... 31

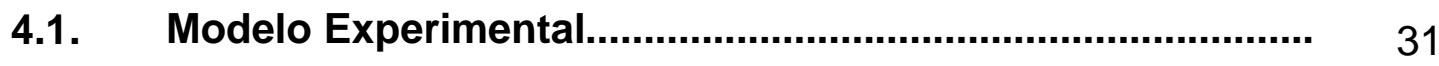

4.2. Pletismografia de Cauda.....................................................

4.3. Imunofluorescência - Calpaína-1 e MMP-2 ……………........ 33

4.4. Western Blot .................................................................... 33

4.5. Ensaio de atividade - Calpaína-1 e MMP-2............................. 34

4.6. Análise histomorfométrica ................................................ 35

4.7. Ecocardiograma.................................................................. 35

4.8. Análise da performance cardíaca pelo modelo de Langendorff

4.9. Análise estatística 
5. RESULTADOS ......................................................... 38

5.1. Verapamil não altera a pressão arterial sistólica nos ratos

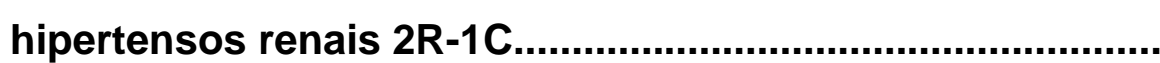

5.2. Verapamil reduz a expressão proteica e atividade de calpaína-1 e MMP-2 no coração durante a hipertensão renovascular

5.3. Verapamil reduz a hipertrofia cardíaca concêntrica induzida por hipertensão renovascular.

5.4. Verapamil não altera a performance cardíaca na sobrecarga pressórica induzida por hipertensão 48 renovascular.

6. DISCUSSÃO

7. CONCLUSÃO. 56

8. REFERÊNCIAS. 


\section{INTRODUÇÃO}

\subsection{Hipertrofia cardíaca na hipertensão arterial}

A hipertrofia cardíaca é uma resposta adaptativa do músculo cardíaco a uma variedade de estímulos fisiopatológicos, de natureza mecânica e hormonal, que levam à sobrecarga hemodinâmica crônica. Como resultado, há um espessamento das paredes das câmaras cardíacas proveniente do aumento no tamanho dos cardiomiócitos e da proliferação do tecido intersticial, o que permite a normalização da tensão nas paredes do miocárdio, de acordo com a Lei de Laplace (SELVETELLA; LEMBO, 2005).

A hipertrofia cardíaca está presente em um grande número de doenças cardiovasculares, incluindo cardiomiopatias genéticas, doença isquêmica do coração, hipertensão arterial sistêmica, insuficiência cardíaca congestiva e doenças valvulares. No contexto da hipertensão arterial, o remodelamento cardíaco hipertrófico está relacionado ao aumento da morbimortalidade de pacientes, consequente à morte súbita, arritmias ventriculares, isquemia miocárdica e disfunções sistólica e diastólica. Assim, faz-se necessário estudar ferramentas farmacológicas que possam reduzir a hipertrofia cardíaca mal adaptativa como fator de risco à hipertensão arterial.

De modo geral, o cardiomiócito hipertrófico está relacionado a um desequilíbrio na homeostase de sistemas de síntese e degradação de proteínas intra- e extracelulares e com a reorganização intensificada dos sarcômeros. Dessa forma, é possível distinguir dois fenótipos hipertróficos: 1) a hipertrofia cardíaca concêntrica, caracterizada pela adição em paralelo dos sarcômeros e o crescimento lateral dos cardiomiócitos, resultando em aumento da espessura da parede ventricular, e 
mudança no volume da câmara cardíaca; 2) a hipertrofia cardíaca excêntrica, que apresenta disposição dos sarcômeros em série, com consequente crescimento longitudinal do cardiomiócito. Estas mudanças resultam em aumento do volume da câmara e espessamento da parede ventricular proporcional às dimensões da câmara. (DORN; ROBBINS; SUGDEN, 2003; FREY et al., 2004). A fração de ejeção é uma importante medida para determinar a performance cardíaca e para diagnosticar e monitorar a insuficiência cardíaca. Entretanto, uma proporção significativa dos pacientes com insuficiência cardíaca possui fração de ejeção normal durante a avaliação por ecocardiografia. Dessa forma, podemos definir dois fenótipos baseados na performance cardíaca: a insuficiência cardíaca com fração de ejeção preservada (do inglês Heart Failure with Preserved Ejection Fraction) e a insuficiência cardíaca com fração de ejeção reduzida (do inglês Heart Failure with Reduced Ejection Fraction) (BLOOM et al., 2017; REDFIELD, 2016).

Diversos mecanismos podem contribuir para o desenvolvimento da hipertrofia cardíaca. A sobrecarga hemodinâmica cardíaca decorrente da hipertensão arterial sugere uma predominância de fatores mecânicos, tais como a tensão e o estiramento de parede, como os principais estímulos para a manutenção da hipertrofia dos cardiomiócitos. Além disso, estudos mostram a participação dos sistemas neurohumorais, tais como o sistema renina-angiotensina-aldosterona e o sistema nervoso autônomo simpático, na evolução da hipertrofia cardíaca associada à sobrecarga pressórica (AKERS et al., 2000; BARKI-HARRINGTON; PERRINO; ROCKMAN, 2004; DOSTAL; BAKER, 1999; TE RIET et al., 2015; WEBER; BRILLA, 1991). Entretanto, o desequilíbrio existente entre os sistemas de síntese e proteólise, que são importantes na manutenção da integridade tecidual e homeostase celular, é um dos principais responsáveis por estas transformações cardíacas durante a hipertensão arterial. A 
atividade acentuada das metaloproteinases da matriz (MMPs) (SCHULZ, 2007) e das calpaínas são exemplos importantes destes sistemas, além da autofagia e a ação do proteassoma (NISHIDA; YAMAGUCHI; OTSU, 2015).

\subsection{As ações das MMPs na hipertrofia cardíaca da hipertensão arterial}

As MMPs pertencem a uma família de proteases dependentes de zinco que estão relacionadas significativamente ao remodelamento da matriz extracelular em vários tecidos, contribuindo diretamente para processos fisiológicos de adaptação e embriogênese e também para algumas condições patológicas, como a hipertensão arterial (BELO; GUIMARÃES; CASTRO, 2015). Dentre as diferentes isoformas das MMPs, a MMP-2 e a MMP-9 participam do remodelamento cardíaco mal adaptativo em modelos experimentais de hipertensão arterial e indução de hipertrofia cardíaca por sobrecarga pressórica. A MMP-2 é geralmente constitutiva e expressa nos cardiomiócitos e fibroblastos na sua forma latente (proMMP-2), em um complexo com seu principal inibidor endógeno, o inibidor tecidual de metaloproteinase do tipo-2 (TIMP-2). Entretanto, também pode ser induzida e ativada por estresse oxidativo e agentes inflamatórios. A MMP-9 é mais comumente expressa em leucócitos, induzida por citocinas pró-inflamatórias (SCHULZ, 2007) e pode ser encontrada em tecidos cardiovasculares após a infiltração leucocitária.

As MMPs, de maneira geral, compartilham a mesma organização de domínios estruturais: a) peptídeo sinalizador na extremidade N-terminal, b) pró-domínio autoinibitório, c) domínio catalítico ligado ao zinco, d) motivo articulador flexível e e) domínio hemopexina na extremidade C-terminal, importante para a interação da MMP2 com outras proteínas, como o TIMP-2 e Hsp90 (do inglês Heat Shock Protein). 
Entretanto, as MMP-2 e -9 apresentam variações estruturais no domínio catalítico, como repetições de domínios tipo II semelhantes à fibronectina, que facilitam a especificidade a alguns substratos como o colágeno tipo IV da membrana basal. Apesar da maioria das MMPs serem proteases solúveis secretadas, há também as MMPs que possuem domínios de ancoragem na membrana plasmática, como a MMP14, MMP-17 e MMP-23 (LU et al., 2011).

As MMPs podem ser ativadas por clivagem proteolítica nos compartimentos extra- e pericelulares. A ativação da forma de zimogênio da MMP-2, a proMMP-2 (72kDa), acontece na superfície celular e é mediada pela MMP-14. Para essa ativação necessita-se da presença do TIMP-2: O TIMP-2 inibe as formas ativas de MMP-2 e MMP-14 por ligação do seu domínio N-terminal inibitório aos sítios ativos destas enzimas. Além disto, uma vez ligado à MMP-14 na membrana celular, o TIMP-2 pode interagir de forma não-covalente com a pro-MMP-2 no domínio hemopexina. A ligação simultânea com a MMP-14 ativa e com a pro-MMP-2 resulta na formação de complexos ternários na superfície celular que permitem a ativação da pro-MMP-2 por outra molécula de MMP-14 vizinha não-ligada ao TIMP-2. Essa interação permite a hidrólise da ligação peptídica asparagina(37)-leucina(38) da pro-MMP-2 gerando uma forma intermediária inativa de MMP-2, que posteriormente é clivada na ligação peptídica asparagina(80)-tirosina(81) por outras MMPs. Esse evento intermolecular leva à ativação completa da MMP-2 (forma de 64kDa) (BERNARDO; FRIDMAN, 2003).

Outros agentes também levam à ativação das MMPs em ensaios in vitro, tais como agentes modificadores de ligação tiol, como os compostos mercuriais, glutationa oxidada, dodecil sulfato de sódio e agentes caotrópicos (VISSE; NAGASE, 2003). Além disso, as espécies reativas de oxigênio e nitrogênio estão envolvidas na ativação 
da MMP-2 por uma via que não necessariamente envolve a remoção do pró-peptídeo auto-inibitório, contribuindo para a proteólise de alvos intracelulares, tais como a titina (ALI et al., 2010) e troponina I (WANG et al., 2002) em modelo de isquemia-reperfusão cardíaca e disfunção celular (SCHULZ, 2007).

Estudos demonstram que as mudanças temporais na estrutura e função do ventrículo esquerdo cardíaco induzidas por sobrecarga pressórica estão associadas ao aumento na expressão e atividade de MMP-2 e -14. Essas MMPs apresentam um papel importante na ativação das vias bioquímicas pró-fibróticas, como integrinas e fator de crescimento transformante (TGF- $\beta$ ), que resultam em deposição cardíaca de colágeno e o remodelamento cardíaco. Além disto, estas MMPs contribuem para amplificação de MMP-2 solúveis, resultando em instabilidade de matriz extracelular e anormalidade de arquitetura tecidual (ZILE et al., 2014).

A inibição da atividade de MMPs como alvo farmacológico tem sido desenvolvida para o tratamento do câncer e doenças inflamatórias (STORR et al., 2011). Fármacos da classe das tetraciclinas, como a doxiciclina, podem inibir a atividade das MMPs por ligar-se ao zinco do sítio catalítico, e assim, preservam a estrutura ventricular esquerda e a função cardíaca total de corações isolados de ratos submetidos a modelo de reperfusão pós-isquêmica (KANDASAMY et al., 2010)

Em modelo transgênico, a expressão cardíaca-específica de MMP-2 ativa, independente da presença de injúrias teciduais, contribuiu para o desenvolvimento da insuficiência cardíaca associado à anormalidade nos cardiomiócitos, disfunção mitocondrial e remodelamento severo do ventrículo esquerdo com diminuição da função sistólica. Essas observações sugerem que a atividade aumentada de MMP-2 tem um efeito causal relacionado a essa patologia (BERGMAN et al., 2006). Outros trabalhos em modelos de hipertensão renovascular demonstraram que a inibição da 
MMP-2 pela doxiciclina contribui para a reversão da hipertrofia do cardiomiócito, do aumento das dimensões ventricular e da disfunção cardíaca (RIZZI et al., 2010).

Figura 1: Representação esquemática dos efeitos do aumento da atividade de MMP-2 nos cardiomiócitos

\section{Normal heart}

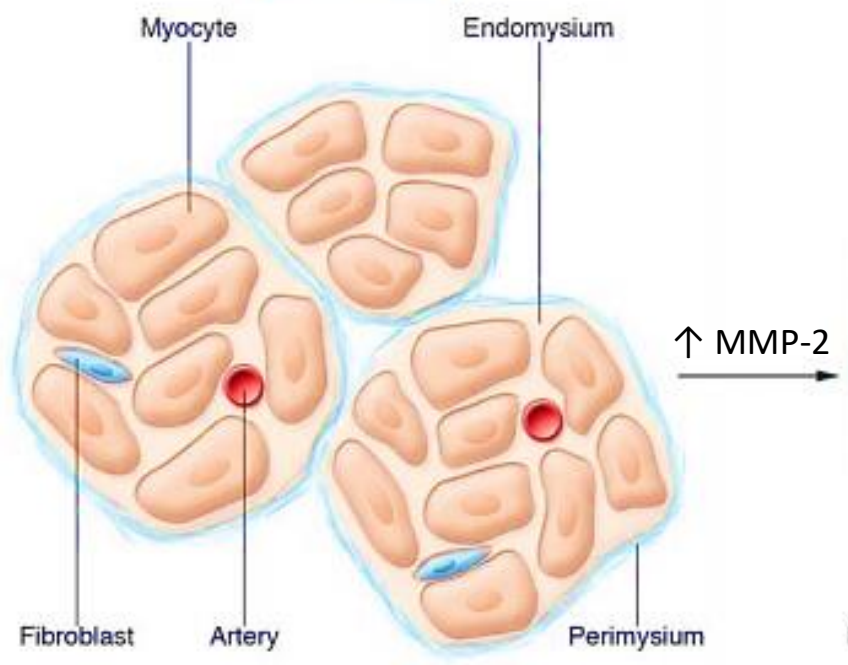

\section{HHD}

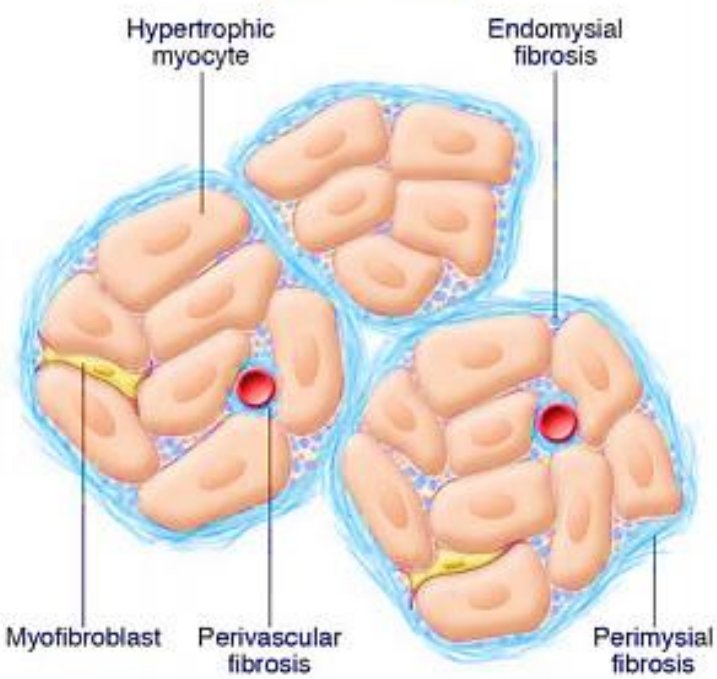

Fonte: Modificado de BERK; FUJIWARA; LEHOUX (2007)

Em aortas de ratos, também em modelo de hipertensão renovascular, foi demonstrado um aumento de atividade de MMP-2 com uma semana de hipertensão arterial que foi revertido com a utilização de doxiciclina. Esse aumento foi relacionado com a diminuição dos níveis de calponina-1, uma proteína responsável pela integridade do citoesqueleto, e com o aumento da proliferação de células musculares lisas, mudanças que precedem o remodelamento arterial crônico. Estes resultados em artérias também mostram a participação da MMP-2 nas alterações mal adaptativas relacionadas à hipertensão arterial (BELO et al., 2016). 


\subsection{Sistema calpaína/calpastatina na hipertrofia cardíaca na hipertensão arterial}

Outro sistema proteolítico associado às modificações hipertróficas do músculo cardíaco é o das calpaínas. Proteases semelhantes à papaína e dependentes de íons cálcio, as calpaínas são membros da família de cisteína proteases não lisossomais, ativadas por cálcio em pH neutro, que são mediadoras críticas das ações do cálcio no compartimento intracelular (PATTERSON et al., 2011). A família pode ser dividida em dois grupos: ubíquas e tecido-específicas. As izoenzimas ubíquas das calpaínas, que estão mais envolvidas na fisiopatologia de doenças cardiovasculares, diferem-se entre si em duas isoformas, micro-( $\mu$-) e mili-(m-) calpaína, dependendo da quantidade de cálcio necessária para suas ativações (PERRIN; VERGELY; ROCHETTE, 2004).

A homeostase do cálcio é particularmente importante nos cardiomiócitos, já que há intensa circulação de cálcio a cada batimento cardíaco. Para que a homeostase ocorra, a mesma quantidade de cálcio que entra na membrana plasmática através dos canais do tipo L durante a contração pode ser removida pelo trocador de sódio/cálcio durante o relaxamento. Um mecanismo similar acontece para a liberação de cálcio pelo retículo sarcoplasmático no meio intracelular com a participação dos receptores de rianodina tipo 2 e da $\mathrm{Ca}^{2+}$-ATPase do retículo sarco/endoplasmático (SERCA). A força de contração do músculo cardíaco, dessa forma, pode ser ajustada pela variação da concentração de cálcio que circula durante o funcionamento do coração. 0 remodelamento cardíaco hipertrófico, portanto, pode ser controlado por várias vias de sinalização dependentes de cálcio, como é o caso da ativação das calpaínas (BERRIDGE; BOOTMAN; RODERICK, 2003). 
Estruturalmente, as calpaínas são proteínas heterodiméricas compostas de uma subunidade maior catalítica de $80 \mathrm{kDa}$ e uma subunidade menor regulatória de 30kDa. A subunidade menor, formada pelos domínios $\mathrm{V}$ e $\mathrm{VI}$, é comum a ambas as isoformas de calpaína. As duas isoformas são distinguidas apenas pela subunidade maior, composta pelos domínios I, II, III e IV. O domínio I, na extremidade N-terminal, contém um sítio autocatalítico envolvido na ativação das calpaínas. O domínio II possui a atividade cisteína protease e é dividido em dois núcleos funcionais, lla e llb, contendo os resíduos de aminoácidos envolvidos na função enzimática, cisteína(105), histidina(262) e ácido aspártico(286). A presença do cálcio permite uma mudança de conformação que aproxima os resíduos de aminoácidos e forma uma fenda de ligação ao substrato, ativando a enzima. Os domínios III e V são regiões de ligação com os fosfolipídios de membrana e contribuem com a ativação das calpaínas, enquanto os domínios IV e VI são motivos EF-hand similares aos da calmodulina e medeiam a fixação dos íons cálcio e a interação entre as duas subunidades (PERRIN; VERGELY; ROCHETTE, 2004; POSTOVIT et al., 2002).

O principal inibidor endógeno a nível intracelular das calpaínas é a calpastatina, que é composta de quatro domínios, cada um responsável pela inibição competitiva de uma molécula de calpaína. Outros inibidores extracelulares identificados incluem a a1-macroglobulina e o cininogênio (PERRIN; VERGELY; ROCHETTE, 2004). Modificações pós-traducionais, como a S-nitrosilação, diminuem a autólise da calpaína e exibem uma inibição da atividade proteolítica sobre os alvos intracelulares da maquinaria contrátil do músculo cardíaco (LIU et al., 2016).

Modelos experimentais de infusão de angiotensina II resultam em desenvolvimento de hipertensão arterial e hipertrofia cardíaca com concomitante aumento da atividade de calpaína-1 e diminuição da calpastatina. Nesse contexto, a 
hipertrofia cardíaca patológica induzida por sobrecarga pressórica ocorre em resposta à estimulação de múltiplas vias de sinalização induzidas pela angiotensina II, nas quais a participação da calpaína-1 ativa é proeminente, tais como a via do NF-kB (do inglês Factor Nuclear kappa B) e NFAT (do inglês Nuclear Factor of Activated T-cells), a via da Akt e a via mediada pela integrina $\beta_{3}$. A diminuição da ativação da calpaína1, por sua vez, previne essa hipertrofia e fibroses cardíaca e perivascular coronariana em modelo animal para superexpressão de calpastina (LETAVERNIER et al., 2008). A calpaína pode atuar ainda na proteólise do canal para cálcio tipo $L$, do trocador de sódio/cálcio e da SERCA, levando à disfunção do sistema de acoplamento excitaçãocontração, e contribuindo com a fibrilação atrioventricular e disritmia (DE JONGH et al., 1994; GLADING; LAUFFENBURGER; WELLS, 2002; LETAVERNIER et al., 2008; LI et al., 2009; PATTERSON et al., 2011; WANICHAWAN et al., 2014).

Figura 2: Representação esquemática das vias de sinalização envolvidas na hipertrofia cardíaca dependente de calpaínas.

Angiotensin II

Endothelin

Norepinephrine

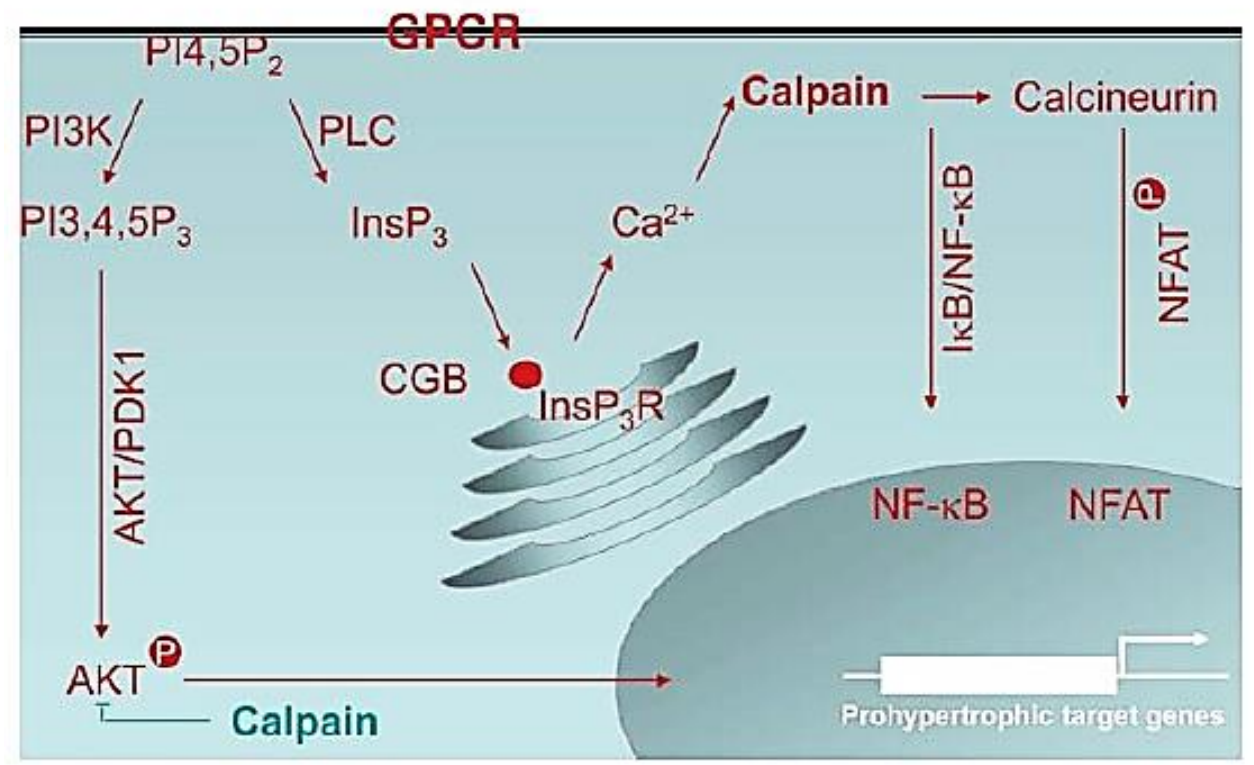

Fonte: LETAVERNIER et al. (2012) 
A calpaína-1 também está relacionada ao aumento da produção de colágeno, fibrose e calcificação distrófica teciduais. Em modelo de hipertensão pulmonar induzida por fármacos ou por hipóxia in vivo e em cultura de células musculares lisas de artérias pulmonares, a atividade aumentada de calpaína-1 foi associada ao aumento da síntese de colágeno a partir da ativação intrácrina da via de sinalização de TGF- $\beta$ (MA et al., 2011). A inibição-alvo da calpaína-1 em modelo de hipertrofia cardíaca induzida por diabetes também contribuiu para a diminuição da expressão proteica de colágeno III e TGF- $\beta$ na parede ventricular (LI et al., 2011).

Em modelos animais de disfunção cardíaca associada à sepse, a utilização de fármacos que interferem na homeostase intracelular do cálcio, como o verapamil, um bloqueador dos canais para cálcio tipo $L$ (BCCL), e o dantrolene, um antagonista dos receptores de rianodina, preveniram o aumento dos níveis de calpaína-1 e reverteram as alterações cardíacas relacionadas à sepse (CELES et al., 2013). O envolvimento dos canais de cálcio do tipo $L$ na ativação das calpaínas também foi demonstrado em modelos experimentais de retinite pigmentosa (NAKAZAWA, 2011; SCHÖN; PAQUET-DURAND; MICHALAKIS, 2016) e doença de Huntington (WILLIAMS et al., 2008), sugerindo a participação de fármacos BCCL na modulação das respostas degenerativas associadas ao aumento da atividade e expressão de calpaína-1.

Existem ainda muitas controvérsias acerca dos substratos preferenciais para os sistemas proteolíticos das calpaínas e das MMPs, sugerindo uma sobreposição de ações biológicas e alvos em diferentes vias de sinalização (KANDASAMY et al., 2010). Há uma certa limitação na identificação precisa dos substratos proteolíticos das calpaínas, já que os inibidores usados em experimentos in vitro e ex-vivo são nãoseletivos e podem inibir também a atividade da MMP-2, assim como alguns inibidores de MMPs, como a doxiciclina e a o-fenantrolina (ALI et al., 2012). Além disto, tais 
inibidores são ferramentas ineficazes para o entendimento da atividade das calpaínas in vivo e não são candidatos atrativos para o manejo clínico, devido sua baixa estabilidade, rápida metabolização e baixa seletividade (STORR et al., 2011). Estas limitações do uso de inibidores de calpaína in vivo nos direcionaram para o verapamil, que foi a ferramenta farmacológica usada nos experimentos aqui apresentados.

\subsection{Regulação da MMP-2 pela calpaína-1}

Muitos dos efeitos cardiovasculares causados pela calpaína-1 talvez sejam conduzidos por outras proteases, como as MMPs. A interação entre os sistemas proteolíticos, calpaína-1 e MMP-2, foi observada em artérias de roedores idosos pela infusão de angiotensina II, que resulta em hipertensão arterial e remodelamento vascular (JIANG et al., 2008). A inibição da atividade da calpaína-1 pelo seu inibidor endógeno, calpastatina, reduziu a atividade aumentada da MMP-2 e a migração celular do tipo mesenquimal (POSTOVIT et al., 2002), por modificar a razão de ativação MMP-14/TIMP-2. Além disto, a superexpressão de calpaína-1 em células musculares lisas vasculares diminui as quantidades proteicas de TIMP-2 e aumenta as de MMP-14, o que aumenta a razão de ativação da MMP-2. Isto faz com que a calpaína-1 possa contribuir para migração celular de forma dependente da MMP-14. A ativação da calpaína-1 altera o estado de polimerização da vimentina, uma proteína que compõe os filamentos intermediários do citoesqueleto celular. Esta proteína pode se complexar com a MMP-14 e estimular sua translocação para a membrana plasmática. Assim, a MMP-14 facilita a ativação de MMP-2, como descrito anteriormente, e contribui para a proteólise do colágeno pela MMP-2, permitindo a migração celular (KANG et al., 2011; KWAK et al., 2012). 
Por outro lado, a superexpressão de TIMP-2 em células musculares lisas vasculares foi capaz de inibir a atividade de MMP-2 e aumentar a expressão proteica de calpaína-1. Além disso, o tratamento com PD166793, um inibidor de MMP, também foi capaz de aumentar a expressão proteica de calpaína-1 nas aortas de ratos jovens, embora reduza a atividade da MMP-2. De forma geral, todos esses dados mostram que a inibição da calpaína-1 parece reduzir os níveis proteicos e a ativação de MMP2, enquanto a inibição de MMP-2 parece levar a um aumento na expressão de calpaína-1 como um evento compensatório, sugerindo que a ativação da MMP-2 é um evento de sinalização secundário à ativação da calpaína-1 (JIANG et al., 2012).

Durante o processo de isquemia e reperfusão cardíaca ex vivo utilizando a metodologia de Langendorff, os autores observaram redução significativa da função cardíaca associada ao aumento da atividade de calpaínas e MMPs. A utilização do inibidor inespecífico de MMPs, doxiciclina, atenuou a disfunção cardíaca sem afetar a atividade aumentada de calpaína. Por outro lado, o uso de inibidores de calpaína (LEU e MDL 28170) foi associado à redução significativa da atividade de MMPs nesses corações, sugerindo que a ativação das MMPs pode ser, em parte, explicada pela ativação da calpaína (SINGH et al., 2012).

Em modelo de hipertrofia cardíaca induzida por diabetes tipo 1 em camundongos, o aumento da atividade de calpaína-1 foi associado à expressão gênica aumentada de marcadores de hipertrofia celular como o fator natriurético atrial (ANF) e a cadeia pesada de miosina. Foi demonstrado nesse estudo que esses fatores estavam associados ao aumento da atividade de NF-kB e NFAT. Além disso, os autores observaram aumento da expressão proteica e atividade de MMP-2 e MMP-9 e diminuição do TIMP-2 nos diferentes modelos de indução de diabetes, o que contribuiu para a disfunção cardíaca observada. A utilização de camundongos que 
superexpressam calpastatina e knock out para calpaína-4, a subunidade reguladora de calpaína-1, e o tratamento farmacológico com inibidor de calpaína-1 contribuíram para a diminuição de todos os parâmetros pró-hipertróficos e, dessa forma, para a melhora do remodelamento e da função cardíaca. Esses dados sugerem que a calpaína-1 talvez contribua para o aumento da expressão proteica e atividade de MMP-2 durante a hipertrofia cardíaca induzida por diferentes modelos (LI et al., 2011). Apesar do aumento da atividade de calpaína-1 e MMP-2 já terem sido observados durante o remodelamento vascular e cardíaco em modelos animais de hipertensão arterial, pouco se sabe sobre a possível interação entre estes sistemas proteolíticos, e se de fato a calpaína modula a atividade da MMP-2 no remodelamento cardíaco hipertrófico concêntrico.

Dessa forma, a hipótese desse trabalho é que o aumento da atividade da calpaína-1 em coração de ratos hipertensos contribua para o aumento da atividade da MMP-2, resultando em hipertrofia ventricular esquerda, disfunção celular celular. 


\section{JUSTIFICATIVA}

Segundo as VI Diretrizes Brasileiras de Hipertensão (NOBRE et al., 2010), a hipertensão arterial sistêmica é uma condição clínica de natureza multifatorial caracterizada por elevação sustentada dos níveis de pressão arterial, frequentemente associada com alterações morfofuncionais de órgãos-alvos e a alterações metabólicas, tendo como consequência o aumento do risco de eventos cardiovasculares fatais e não-fatais. A hipertensão arterial sistêmica apresenta alta prevalência e baixas taxas de controle, além de ser considerada um dos principais fatores de risco modificáveis e um importante problema de saúde pública, atendendo por cerca de 7,6 milhões de mortes no mundo, a maioria em países de baixo e médio desenvolvimento econômico, sendo que no Brasil é a principal causa de morte.

O remodelamento hipertrófico cardíaco, resultante da sobrecarga hemodinâmica imposta ao coração pela hipertensão arterial sistêmica, tem importância visto que sua presença está relacionada ao aumento da morbimortalidade dos pacientes, e apesar da extensa literatura acerca do assunto, muito ainda necessita ser elucidado no que diz respeito aos mecanismos que levam ao desenvolvimento dessas alterações decorrentes da condição hipertensiva.

Muitos estudos abordam o envolvimento dos sistemas proteolíticos como agentes importantes no desenvolvimento dessas alterações mal adaptativas resultantes da hipertensão arterial. O desequilíbrio na ativação de diversos componentes desses sistemas tais como a calpaína-1 e a MMP-2, e a interação existente entre os diferentes sistemas contribui para a reorganização da matriz extracelular e a disfunção contrátil observada em cardiomiócitos, levando à manutenção do quadro hipertensivo. 


\section{OBJETIVO GERAL}

Verificar se a calpaína-1 pode contribuir com o aumento da expressão proteica e/ou atividade de MMP-2 no coração, e se estas proteases contribuem para as alterações morfofuncionais cardíacas crônicas da hipertensão arterial, que podem resultar em hipertrofia ventricular esquerda.

\subsection{Objetivos específicos}

- Verificar se a hipertrofia cardíaca induzida por hipertensão renovascular está relacionada ao aumento da atividade e expressão proteica de calpaína-1 e MMP-2;

- Verificar se a modulação da atividade e expressão proteica de calpaína-1 com o verapamil é capaz de modular a atividade e expressão de MMP-2 e reduzir as alterações morfofuncionais observadas no coração durante a hipertensão arterial. 


\section{MATERIAIS E MÉTODOS}

\subsection{Modelo Experimental}

Ratos Wistar machos, livres de germes patogênicos específicos (SPF), com variação de peso entre 180 a 200g, foram obtidos do Biotério Central do Campus de Ribeirão Preto da Universidade de São Paulo (USP). Os animais foram mantidos no biotério setorial do Departamento de Fisiologia da FMRP-USP em condições controladas, tais como ciclo claro/escuro de 12 horas a $25^{\circ} \mathrm{C}$, com livre acesso à água e ração para roedores. Todos os protocolos foram conduzidos de acordo com as resoluções do Comitê de Ética em Pesquisa Animal da Faculdade de Medicina de Ribeirão Preto (43/2017).

A hipertensão renovascular $2 \mathrm{R}-1 \mathrm{C}$ foi induzida através da implantação de um clipe de prata $(0,2 \mathrm{~mm}$ de abertura) na artéria renal esquerda, conforme descrito por Goldblatt (GOLDBLATT, 1958). A estenose renal parcial resultante dessa metodologia leva à ativação do sistema renina-angiotensina-aldosterona, com consequente aumento de pressão arterial. Em um grupo de animais, o procedimento cirúrgico foi realizado após anestesia geral via intraperitoneal com ketamina $(100 \mathrm{mg} / \mathrm{kg})$ e xilazina (10mg/kg). O outro grupo passou por um procedimento cirúrgico de laparotomia nas mesmas condições anestésicas sem implementação do clipe, caracterizando o grupo normotenso. A pressão arterial sistólica (PAS) foi mensurada por pletismografia de cauda semanalmente e os animais que apresentaram PAS maior ou igual a $160 \mathrm{mmHg}$ em relação aos parâmetros basais pré-cirúrgicos, na segunda semana do protocolo, foram considerados hipertensos. Foi implementado o tratamento oral por gavagem com cloridrato de verapamil (VRP) [dose de 8mg/kg/bid (SANDMANN et al., 2001)] 
durante 8 semanas. O verapamil foi escolhido por modular as concentrações de cálcio intracelulares em diferentes modelos animais (NAKAZAWA, 2011; SCHÖN; PAQUETDURAND; MICHALAKIS, 2016; WILLIAMS et al., 2008). Ao fim, os animais foram eutanasiados para obtenção do coração e avaliação dos parâmetros morfofuncionais e bioquímicos da hipertrofia. Esta dose foi escolhida com o objetivo de avaliar os mecanismos celulares envolvidos na hipertrofia, sem a interferência da pressão arterial.

Grupos experimentais:

- Sham + veículo - normotensos tratados com água (veículo);

- Sham + VRP - normotensos tratados com verapamil;

- $2 \mathrm{R}-1 \mathrm{C}+$ veículo - hipertensos, tratados com veículo;

- $2 \mathrm{R}-1 \mathrm{C}+\mathrm{VRP}-$ hipertensos tratados com verapamil.

\subsection{Pletismografia de Cauda}

Para mensuração da PAS e progressão semanal da hipertensão arterial foi utilizada pletismografia de cauda. Os animais foram dispostos em contensores apropriados ao peso sobre uma placa aquecida a $37^{\circ} \mathrm{C}$. Os manguitos foram colocados na base da cauda e ligados a um sistema de aquisição de dados (CODA non-invasive blood pressure system, Version 1.1, 2007, Kent Scientific Incorporation, Connecticut, Estados Unidos). 


\subsection{Imunofluorescência - Calpaína-1 e MMP-2}

Os corações foram criosseccionados $(5 \mu \mathrm{m})$ e fixados em acetona gelada por 5 minutos. As secções de coração foram lavadas com PBS (0.1M) seguida de duas lavagens com Triton-X 100 (0.3\%, v/v, pH 7.3). As amostras foram bloqueadas com soro de burro (10\%, v/v, \#S-30, Millipore, EUA) por 1 hora. Em seguida, foram incubadas com anticorpos primários anti-calpaína-1 de coelho e anti-MMP-2 de camundongo por 1 hora em câmara escura úmida. Os anticorpos secundários anticoelho Alexa 488 (1:250, A21206, Life techonologies, EUA) e anti-camundongo Cy3 (diluição 1:250, AP192C, Millipore, EUA) foram usados por 1 hora nas mesmas condições anteriores e seguidas de duas lavagens com PBS e Triton-X 100. As imagens foram obtidas com microscopia de fluorescência (Leica DMI6000B, Heerbrugg, Suíça) e capturadas no aumento de 40x. Secções de coração do grupo Sham + veículo que foram incubadas somente com anticorpos primários ou com anticorpos secundários foram utilizadas como controle negativo.

\subsection{Western Blot}

As amostras de ventrículo esquerdo foram previamente trituradas e foi obtido o sobrenadante por centrifugação (13000 rpm, 10 min, 4ํㅡ). A quantidade de proteínas obtidas no sobrenadante foi mensurada pelo método de Bradford (BRADFORD, 1976). $5 u \mathrm{~g} / \mathrm{ml}$ de proteína, misturados em tampão desnaturante $2 X$, foram aplicados em gel SDS-PAGE 10\% por eletroforese. Em seguida, as proteínas foram transferidas

para membranas de nitrocelulose (Amersham Protran 0,45 $\mu \mathrm{m}$, 10600002, GE Healthcare, Suécia) em tampão de transferência (Tris 48mM, ácido aminoacético 
$39 \mathrm{mM}$, dodecilsulfato de sódio $0,04 \%$, v/v, álcool metílico 20\%, v/v). As membranas foram incubadas com anticorpos primários contra calpaína-1 (diluição 1:5000, ab39170, Abcam, Reino Unido), após bloqueio da membrana com leite desnatado (5\%, p/v, Blotting-Grade Blocker, \#170-6404, BioRad, EUA) por 1 hora, por um período de 16 a 20 horas. As membranas foram lavadas 3 vezes com solução tampão TrisSalina + Tween $(0,1 \%)$ para posterior incubação com anticorpo secundário, anticoelho (diluição 1:6000, \#12-348, Millipore, EUA). As bandas foram identificadas por quimioluminescência (Amersham Imager 600, GE Healthcare, Suécia) com reagente ECL (Immobilon Western, WBKLS0500, Millipore, EUA) e quantificadas através do software Image $\mathrm{J} \circledast$. As bandas foram normalizadas a partir da marcação de bandas para anticorpo para proteína ribossomal S6 (diluição 1:5000, \#2217S, Cell Signaling, EUA).

\subsection{Ensaio de atividade - Calpaína-1 e MMP-2}

As amostras de ventrículo esquerdo cardíaco (60ug de proteína/amostra) foram aplicadas em gel de poliacrilamida 10\% contendo $2 \%$ caseína (substrato para calpaínas) ou 1\% gelatina (substrato para MMP-2) e submetidas à eletroforese. Em seguida, o gel de caseína foi incubado com tampão de ativação (25mM MOPS, 5mM $\beta$-mercaptoetanol, $5 \mathrm{mM}$ cloreto de cálcio, $\mathrm{pH} 7,5)$ overnight em temperatura ambiente. O gel de gelatina foi incubado com solução detergente $2 \%$ v/v Triton X-100 durante 1 hora com duas trocas de tampão a cada 30 minutos em temperatura ambiente. Após isso, o gel de gelatina foi incubado com tampão de ativação 50mM Tris- $\mathrm{HCl}$ contendo $10 \mathrm{mM}$ cloreto de cálcio overnight a $37^{\circ} \mathrm{C}$. Os géis foram corados com $0,05 \%$ azul de Coomassie. Foram utilizados controles positivos com extrato de músculo femoral 
(para calpaínas) e soro fetal bovino (para MMP-2). A quantificação das bandas foi feita por densitometria por software ImageJ (CROALL; MOFFETT; HATCH, 2002; PARENTE et al., 2017).

\subsection{Análise histomorfométrica}

Os ventrículos dos corações obtidos durante a eutanásia dos animais foram perfundidos com solução de Krebs-Henseleit ( $\mathrm{NaCl} 118 \mathrm{mM} ; \mathrm{KCl} 4,7 \mathrm{mM} ; \mathrm{KH}_{2} \mathrm{PO}_{4}$ 1,2mM; $\mathrm{MgSO}_{4.7 \mathrm{H}_{2} \mathrm{O}}$ 1,2 mM; $\mathrm{CaCl}_{2} .2 \mathrm{H}_{2} \mathrm{O}$ 1,25mM; EDTA 0,5 mM; $\mathrm{NaHCO}_{3}$ 25mM; Dextrose $11 \mathrm{mM}$; pH 7,4) para retirada de sangue e, em seguida, com solução de $\mathrm{KCl}$ $1 \mathrm{M}$ para parada cardíaca em diástole. Os corações foram pesados e o valor de massa dividido ao peso corporal para verificação do aumento de massa cardíaca observada na hipertrofia.

Para obtenção dos dados morfométricos, cortes transversais do ventrículo esquerdo foram corados com Hematoxilina-Eosina e imagens foram capturadas através de uma digitalizadora (1200 dpi). Foram quantificadas a espessura da secção transversal do ventrículo esquerdo e do septo interventricular espessura da parede $=$ [(perímetro externo da parede ventricular + perímetro interno da parede ventricular /2) / área total da parede ventricular]\} para verificação dos parâmetros hipertróficos.

\subsection{Ecocardiograma}

Para a análise morfofuncional do coração in vivo foi utilizado o ecodopplercardiograma Vevo 2100 System (Visual Sonics, Toronto, ON M4N 3N1, Canada) com sonda de $30 \mathrm{MHz}$. Os animais foram anestesiados com a mistura de 
$1,5 \%$ isoflurano vaporizado em $1 \%$ de oxigênio. Os animais foram colocados em uma placa aquecida $\left(37-40^{\circ} \mathrm{C}\right)$ e as patas conectadas a eletrodos. Com a visualização bidimensional do ventrículo esquerdo em eixo longo foram obtidas imagens em ModoM para a análise dos seguintes parâmetros cardíacos (em $\mathrm{mm}$ ): diâmetro interno do ventrículo esquerdo durante a sístole e a diástole, espessura da parede anterior e posterior do ventrículo esquerdo durante a sístole e diástole. A fração de encurtamento (\%) e a fração de ejeção (\%) foram calculadas a partir da obtenção desses valores utilizando-se do método de Teichholz.

\subsection{Análise da performance cardíaca pelo modelo de Langendorff}

O modelo de Langendorff proposto foi uma modificação do modelo de coração isolado e perfundido originalmente descrito por Oscar Langendorff (1895). Em resumo, os animais foram anestesiados com uretana $10 \%$ por via intraperitoneal para remoção do coração, preservando-se os grandes vasos da base. O coração foi então perfundido de maneira retrógrada via aorta por fluxo contínuo (10 ml/min) com solução oxigenada (95\% de $\mathrm{O}_{2} ; 5 \%$ de $\left.\mathrm{CO}_{2}\right)$ de Krebs-Henseleit $(\mathrm{NaCl} 118 \mathrm{mM} ; \mathrm{KCl} 4,7 \mathrm{mM}$; $\mathrm{KH}_{2} \mathrm{PO}_{4}$ 1,2mM; $\mathrm{MgSO}_{4} .7 \mathrm{H}_{2} \mathrm{O}$ 1,2 mM; $\mathrm{CaCl}_{2} .2 \mathrm{H}_{2} \mathrm{O}$ 1,25mM; EDTA 0,5 mM; $\mathrm{NaHCO}_{3}$ 25mM; Dextrose $11 \mathrm{mM}$; pH 7,4) enriquecida com ácido caprílico $(0,05 \mathrm{mM})$, a $37^{\circ} \mathrm{C}$. A pressão retrógrada causa o fechamento da válvula aórtica, permitindo que a soluçãotampão supra o tecido cardíaco em nutrientes e oxigênio através da circulação coronariana. Isto preserva o funcionamento cardíaco ex vivo. A frequência cardíaca foi mantida constante por meio de um estimulador elétrico. Os parâmetros de contratilidade cardíaca (pressão sistólica desenvolvida do ventrículo esquerdo, dP/dt máxima e dP/dt mínima) foram adquiridos através da inserção de um balão de látex 
preenchido com água no ventrículo esquerdo via válvula mitral. O balão foi conectado a um transdutor de pressão acoplado a um sistema de aquisição de dados. Após um período de estabilização, o balão foi inflado de modo progressivo, levando a aumentos gradativos na pressão diastólica, a fim de mimetizar a Lei de Frank-Starling. O fluxo coronariano foi aferido pelo volume por minuto do efluente proveniente das cavidades cardíacas (BELL; MOCANU; YELLON, 2011).

\subsection{Análise estatística}

Os resultados foram expressos como média \pm desvio padrão da média. Comparações foram feitas utilizando análise de variância de duas vias seguida de pós-teste de Bonferroni em software Graphpad Prism 6.01. Valores de probabilidade de $5 \%$ foram considerados significativos. 


\section{RESULTADOS}

\subsection{Verapamil não altera a pressão arterial sistólica nos ratos hipertensos renais $2 R-1 C$}

Ao longo das dez semanas de hipertensão renovascular, a avaliação da PAS demonstrou um aumento sustentado significativo nos ratos $2 \mathrm{R}-1 \mathrm{C}$ quando comparados ao grupo controle Sham. O tratamento com verapamil não foi capaz de reduzir esta pressão elevada nos ratos 2R-1C (Sham(10): 120,80 $\pm 5,43$; Sham + $\operatorname{VRP}_{(10)}: 116,35 \pm 3,29 ; 2 R-1 C_{(10)}: 208,68 \pm 7,37 ; 2 R-1 C+V R P: 211,01 \pm 6,77 ; n=9-$ 10, $p<0,05)$ (Figura 3A).

Ademais, ao final de 10 semanas de hipertensão renovascular não foi encontrada alteração significativa no peso corporal dos animais (Sham(10): 540,50 \pm 21,53; Sham + VRP(10): $576,00 \pm 18,69 ; 2 R-1 C_{(10)}: 538,33 \pm 38,14 ; 2 R-1 C+\operatorname{VRP}_{(10)}$ : $466,00 \pm 16,48 ; n=9-10)$ (Figura 3B). 
A

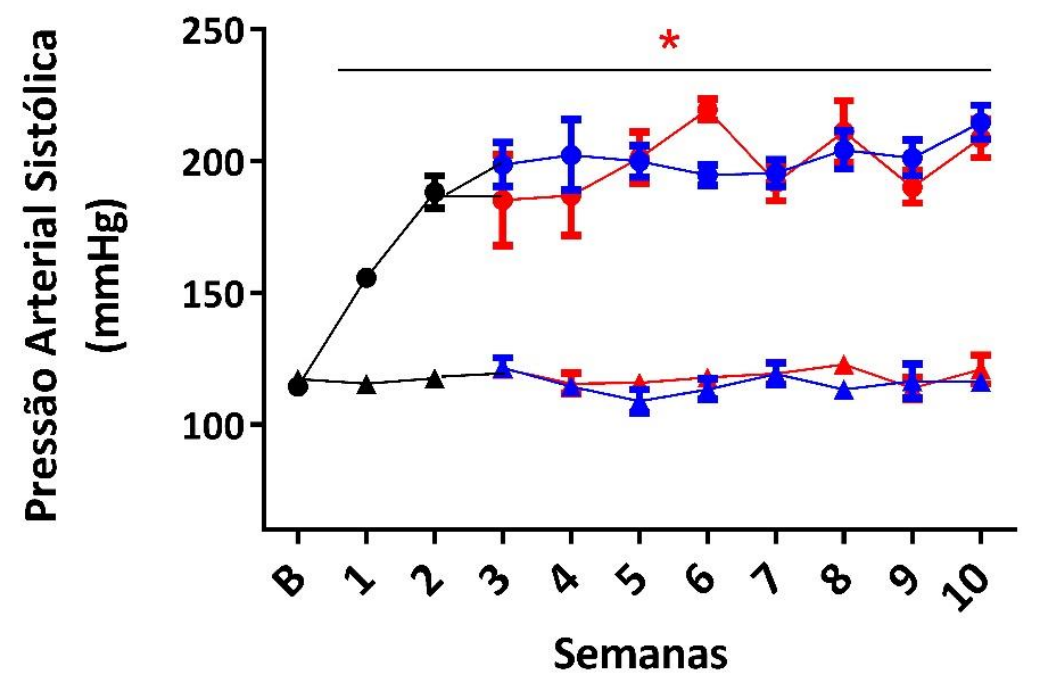

$\leftarrow$ Sham $(n=20)$

- $2 R-1 C(n=19)$

$\rightarrow$ Sham + veículo $(n=10)$

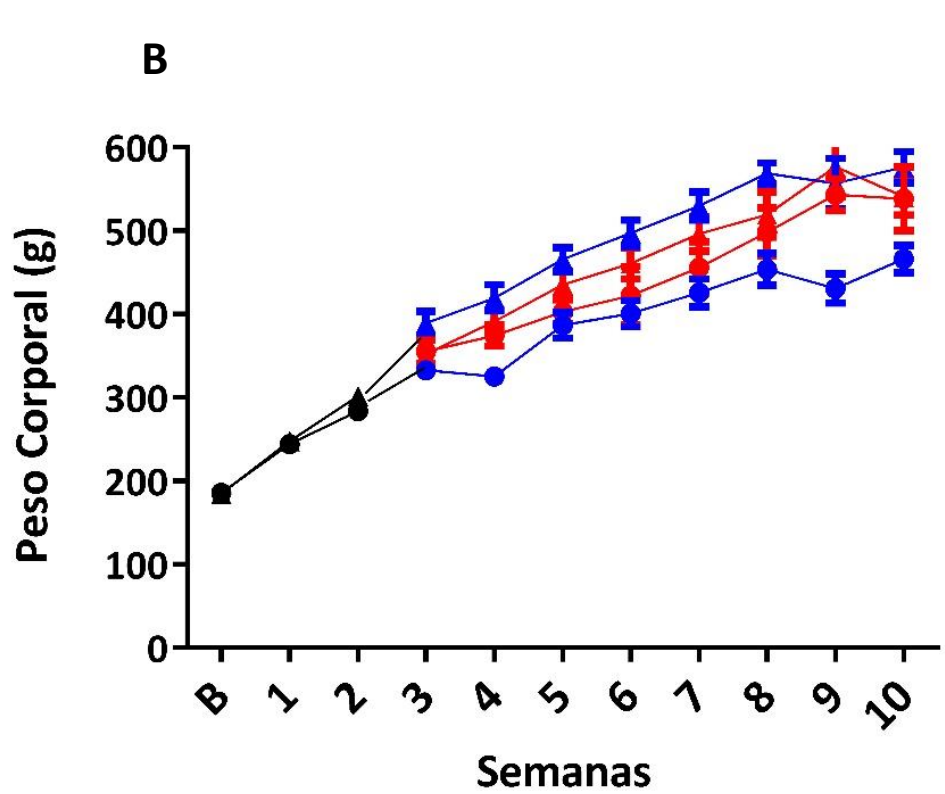

- Sham + VRP $(\mathrm{n}=10)$

- $2 R-1 C+$ veículo $(n=9)$

$\rightarrow 2 R-1 C+\operatorname{VRP}(n=10)$

Semanas

Figura 3: Avaliação da pressão arterial sistólica (A) e do peso corporal (B) dos animais ao longo das dez semanas de hipertensão renovascular e tratamento com cloridrato de verapamil $(8 \mathrm{mg} / \mathbf{k g} /$ bid) por gavagem. Os dados são apresentados como médias \pm EPM ( $\mathrm{n}$ $=9-10$ por grupo, ${ }^{*} p<0,05$ versus Sham e Sham + VRP). Legenda: B: Basal; VRP: Verapamil. 


\subsection{Verapamil reduz a expressão proteica e atividade de calpaína-1 e MMP-2 no coração durante a hipertensão renovascular}

A expressão proteíca de calpaína-1 foi analisada como potencial mecanismo que contribui para o aumento da expressão proteica e atividade enzimática de MMP2 induzida pela sobrecarga pressórica da hipertensão arterial. A expressão proteica significativamente aumentada de calpaína-1 foi observada no músculo cardíaco de ratos hipertensos quando comparada aos controles Sham, e este efeito foi reduzido com a administração de verapamil $\left(\operatorname{Sham}_{(10)}: 20,54 \pm 0,71\right.$; Sham $+\operatorname{VRP}_{(10)}: 21,28 \pm$ 1,$\left.80 ; 2 R-1 C_{(10)}: 33,47 \pm 2,35 ; 2 R-1 C+V P_{(10)}: 25,61 \pm 2,17 ; n=5-6, p<0,05\right)$ (Figura 4C). Esses dados foram corroborados com a avaliação da expressão proteíca de calpaína-1 por western blot. Observou-se redução significativa das quantidades aumentadas de calpaína-1 no coração dos ratos hipertensos quando tratados com verapamil (Sham(10): 0,52 $\pm 0,05$; Sham + VRP $(10): 0,40 \pm 0,03 ; 2 R-1 C_{(10)}: 0,75 \pm 0,09$; $\left.2 R-1 C+\operatorname{VRP}_{(10)}: 0,42 \pm 0,03 ; n=5, p<0,05\right)($ Figura $4 A)$.

A atividade de calpaína-1, realizada por zimografia em gel copolimerizado com caseína, também foi avaliada e demonstrou-se aumentada significativamente nos animais hipertensos quando comparados aos controles Sham. A dose utilizada de verapamil reduziu esta atividade aumentada de calpaína-1 nos ratos 2R-1C (Sham(10): $750,80 \pm 48,10 ;$ Sham + VRP $(10): 679,00 \pm 39,40 ; 2 R-1 C_{(10)}: 1470,00 \pm 112,20 ; 2 R-1 C$ $\left.+\operatorname{VRP}_{(10)}: 921,80 \pm 154,50 ; n=4-7, p<0,05\right)($ Figura 4B)

A expressão proteica de MMP-2 foi avaliada como potencial mecanismo efetor na hipertrofia cardíaca concêntrica induzida por sobrecarga pressórica, por contribuir na degradação de alvos proteicos da matriz extracelular, tais como as fibras colágenas tipo I. A expressão proteica significativamente aumentada de MMP-2 foi observada no 
coração de animais hipertensos $2 \mathrm{R}-1 \mathrm{C}$ quando comparada ao grupo controle Sham. A administração de verapamil foi capaz de reduzir o aumento da expressão proteica de MMP-2 nos animais $2 R-1 C$ (Sham $(10): 17,32 \pm 0,59$; Sham + VRP(10): $18,21 \pm 0,66$; $\left.2 R-1 C_{(10)}: 20,91 \pm 0,78 ; 2 R-1 C+V_{R P}(10): 17,78 \pm 0,82 ; n=6, p<0,05\right)$ (Figura 5B).

A avaliação da atividade de MMP-2, realizada por zimografia em gel copolimerizado com gelatina, demonstrou um aumento significativo da atividade gelatinolítica das isoformas de 64kDa e 72kDa da MMP-2 nos extratos de ventrículo esquerdo de animais hipertensos quando comparados aos controles. O tratamento com verapamil reduziu significativamente a atividade aumentada da 64kDa MMP-2 nos ratos hipertensos $\left(S_{\text {Sham }}(10): 0,019 \pm 0,003\right.$; Sham $+V_{R P}(10): 0,018 \pm 0,005 ; 2 R-$ $\left.1 C_{(10)}: 0,045 \pm 0,009 ; 2 R-1 C+\operatorname{VRP}_{(10)}: 0,023 \pm 0,005 ; n=5-6, p<0,05\right)$. Não houve alteração das quantidades proteicas de 72kDa MMP-2 nos animais hipertensos depois de tratados com verapamil $\left(\operatorname{Sham}_{(10)}\right): 0,21 \pm 0,01$; Sham $\left.+\operatorname{VRP}_{(10)}\right): 0,19 \pm 0,02 ; 2 R-$ $\left.1 C_{(10)}: 0,37 \pm 0,04 ; 2 R-1 C+V_{R P}(10): 0,33 \pm 0,03 ; n=5-6, p<0,05\right)$ (Figura $5 A$ ). 


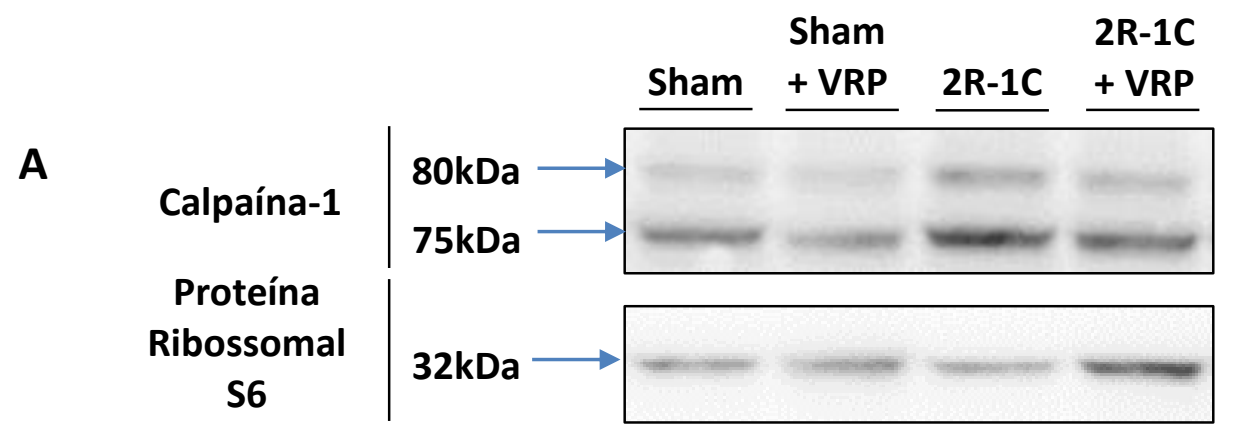

B

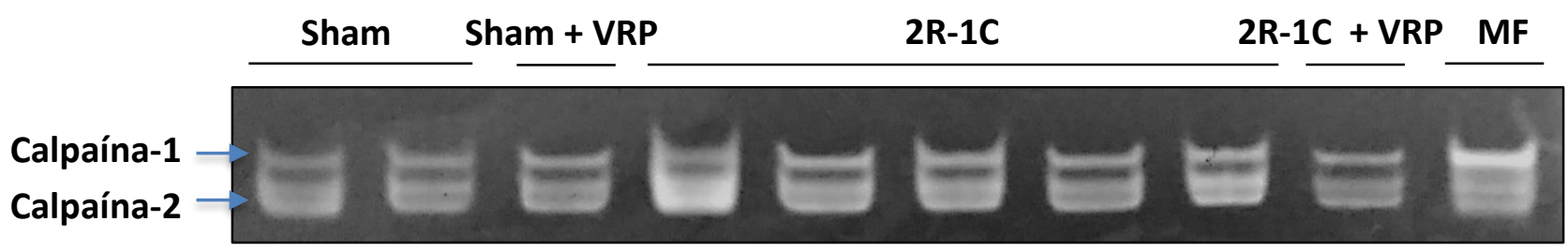

C

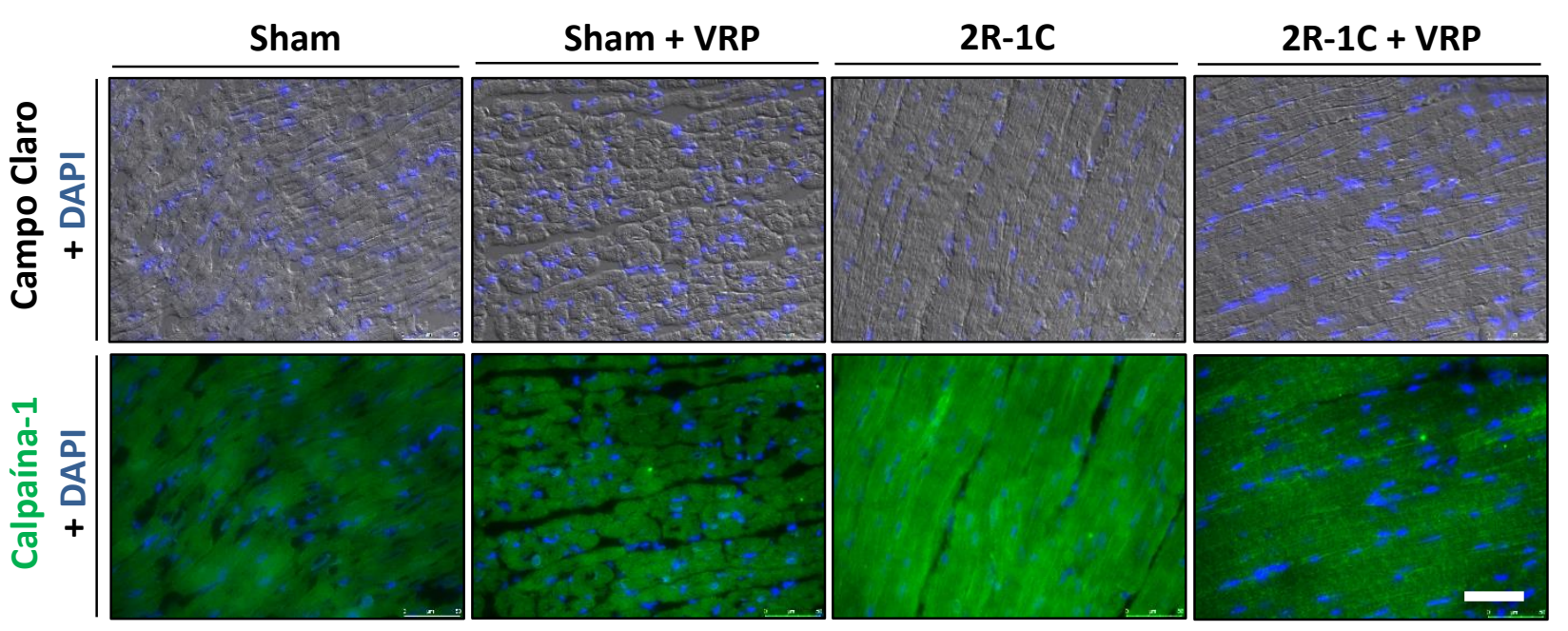

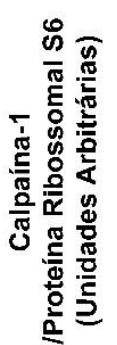
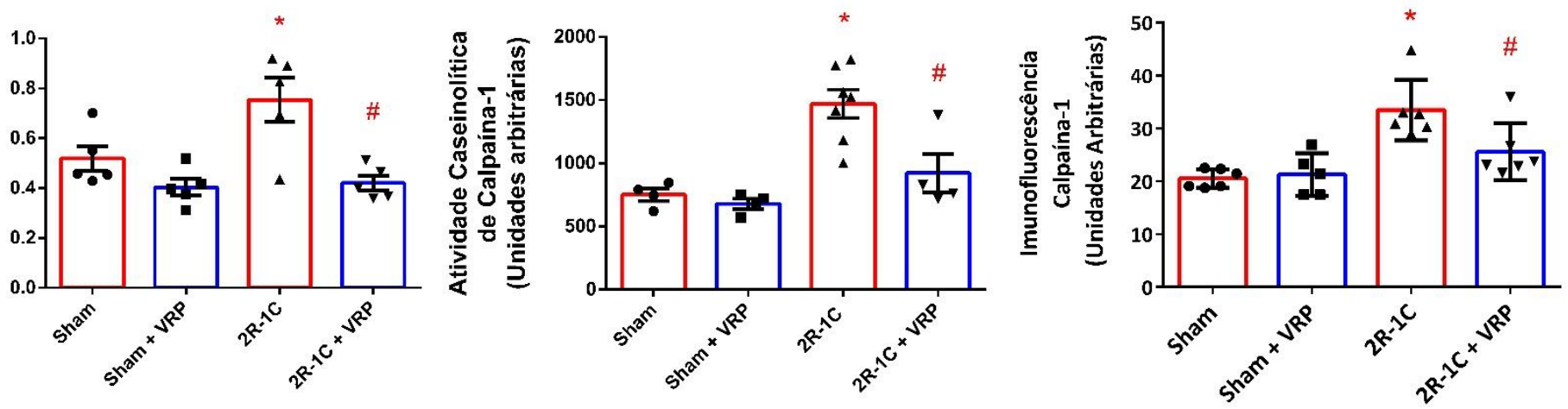

Figura 4: Expressão proteica de calpaína-1 por Western blot (A) e por imunofluorescência (C) e avaliação da atividade caseinolítica por zimografia em gel das isoformas de calpaína (B) no ventrículo esquerdo dos animais submetidos à hipertensão renovascular por dez semanas e tratamento com cloridrato de verapamil $(8 \mathrm{mg} / \mathbf{k g} / \mathbf{b i d})$ por gavagem. Os dados são apresentados como médias \pm EPM $(n=4-7$ por grupo, * $p<0,05$ versus Sham e Sham + VRP; $\# p<0,05$ versus $2 R-1 C$ ) Legenda: MF: músculo femoral; VRP: Verapamil. 


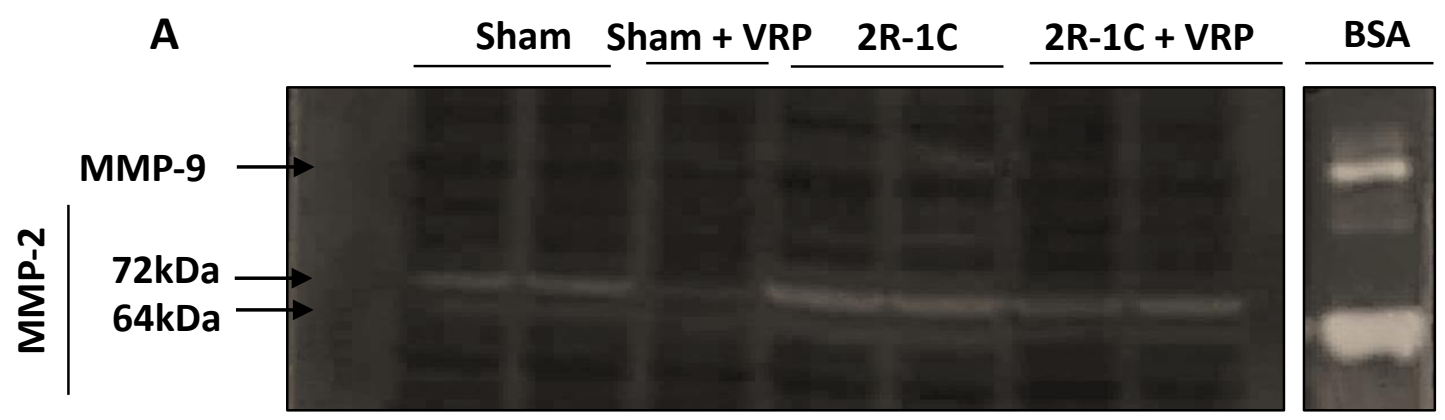

B
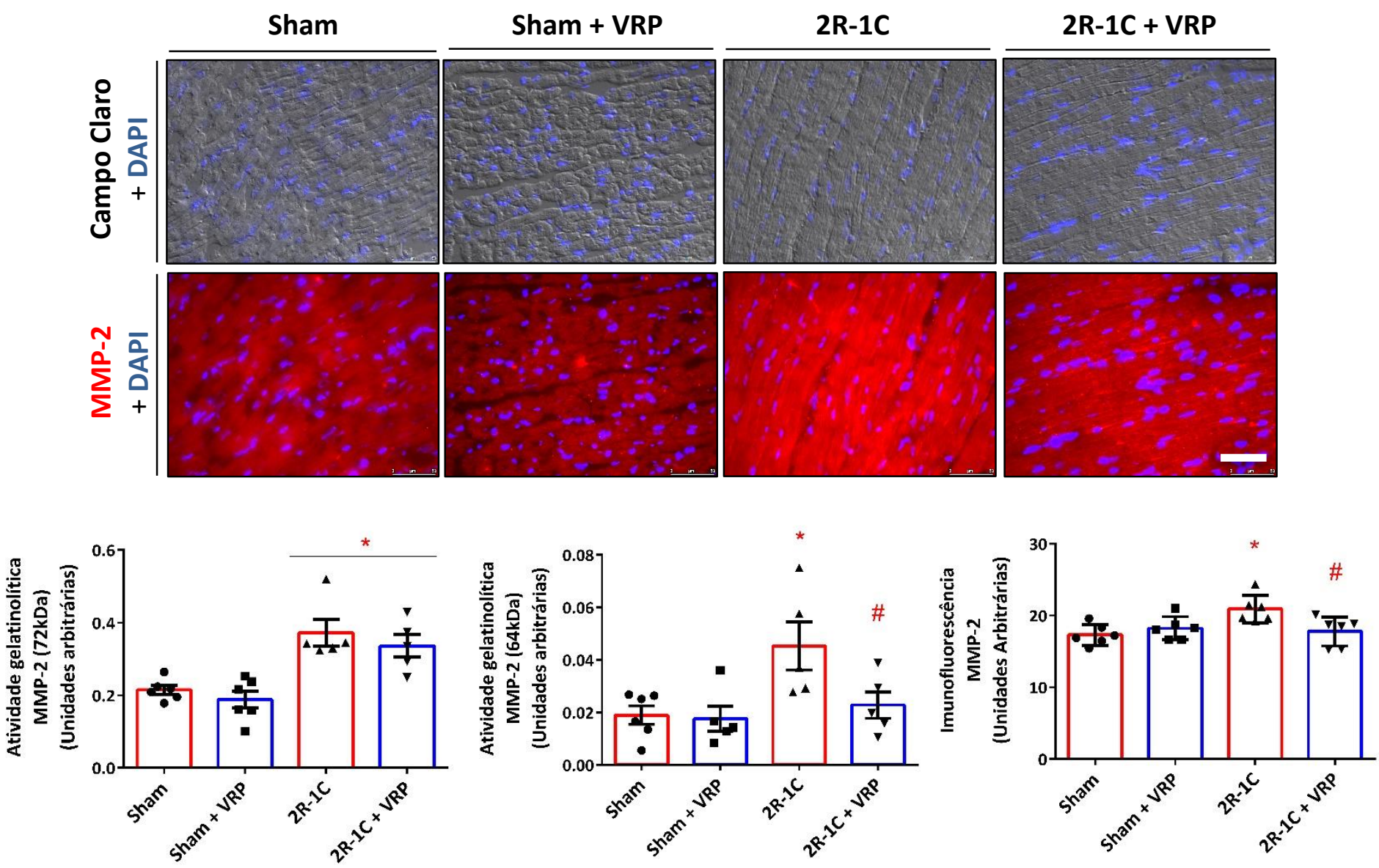

Figura 5: Avaliação da atividade gelatinolítica por zimografia em gel das isoformas de MMP-2 (A) e expressão proteica de MMP-2 por imunofluorescência (B) no ventrículo esquerdo dos animais submetidos à hipertensão renovascular por dez semanas e tratamento com cloridrato de verapamil $(8 \mathrm{mg} / \mathrm{kg} / \mathrm{bid})$ por gavagem. Os dados são apresentados como médias \pm EPM $\left(n=4-7\right.$ por grupo, ${ }^{*} p<0,05$ versus Sham e Sham + VRP; $\# p<0,05$ versus $2 \mathrm{R}-1 \mathrm{C}$ ) Legenda: BSA: soro fetal bovino; VRP: Verapamil. 


\subsection{Verapamil reduz a hipertrofia cardíaca concêntrica induzida por hipertensão renovascular}

O aumento na expressão proteica de calpaína-1 e MMP-2 e ativação extracelular de MMP-2 podem contribuir para a disfunção e remodelamento cardíacos induzidos por sobrecarga pressórica. Na figura 6, observa-se um aumento da razão peso ventricular pelo peso corporal dos animais hipertensos quando comparados aos controles. O tratamento com verapamil reduziu o aumento de massa cardíaca característico da hipertrofia cardíaca nos animais hipertensos (Sham(10): $3,15 \pm 0,07$; Sham + VRP(10): $3,11 \pm 0,09 ; 2 R-1 C_{(10)}: 5,02 \pm 0,45 ; 2 R-1 C+\operatorname{VRP}_{(10)}: 4,20 \pm 0,12 ; n=$ $6-10, p<0,05)$.

A avaliação da espessura do ventrículo esquerdo cardíaco também foi avaliada por histologia e coloração com hematoxilina-eosina e mostrou um aumento das dimensões da parede posterior (parede livre) do ventrículo esquerdo nos animais hipertensos quando comparados aos controles. $O$ tratamento com verapamil reduziu este aumento da espessura cardíaca nos ratos $2 \mathrm{R}-1 \mathrm{C}\left(\operatorname{Sham}_{(10)}\right.$ : 2,33 $\pm 0,14$; Sham + $\operatorname{VRP}_{(10)}: 2,54 \pm 0,16 ; 2 R-1 C_{(10)}: 2,94 \pm 0,24 ; 2 R-1 C+\operatorname{VRP}_{(10)}: 2,25 \pm 0,16 ; n=4-8$, $\mathrm{p}<0,05$ )(Figura 6). Por outro lado, a espessura da parede anterior (septo interventricular) do ventrículo esquerdo não apresentou diferença estatística entre os grupos. A avaliação morfológica in vivo por meio da ecocardiografia corrobora estes dados histológicos (Figura 7). A espessura das paredes anterior (PAVE) e posterior (PPVE) do ventrículo esquerdo cardíaco durante a sístole e a diástole apresentou-se aumentada nos animais 2R-1C em relação aos animais dos grupos controles. Como consequência da hipertrofia cardíaca na hipertensão arterial, o diâmetro interno da câmara cardíaca esquerda (DIVE) dos ratos 2R-1C apresentou-se diminuído em 
ambas as fases do ciclo cardíaco. O tratamento com verapamil reduziu essas alterações hipertróficas observadas nas paredes e na câmara ventriculares (Tabela 1).
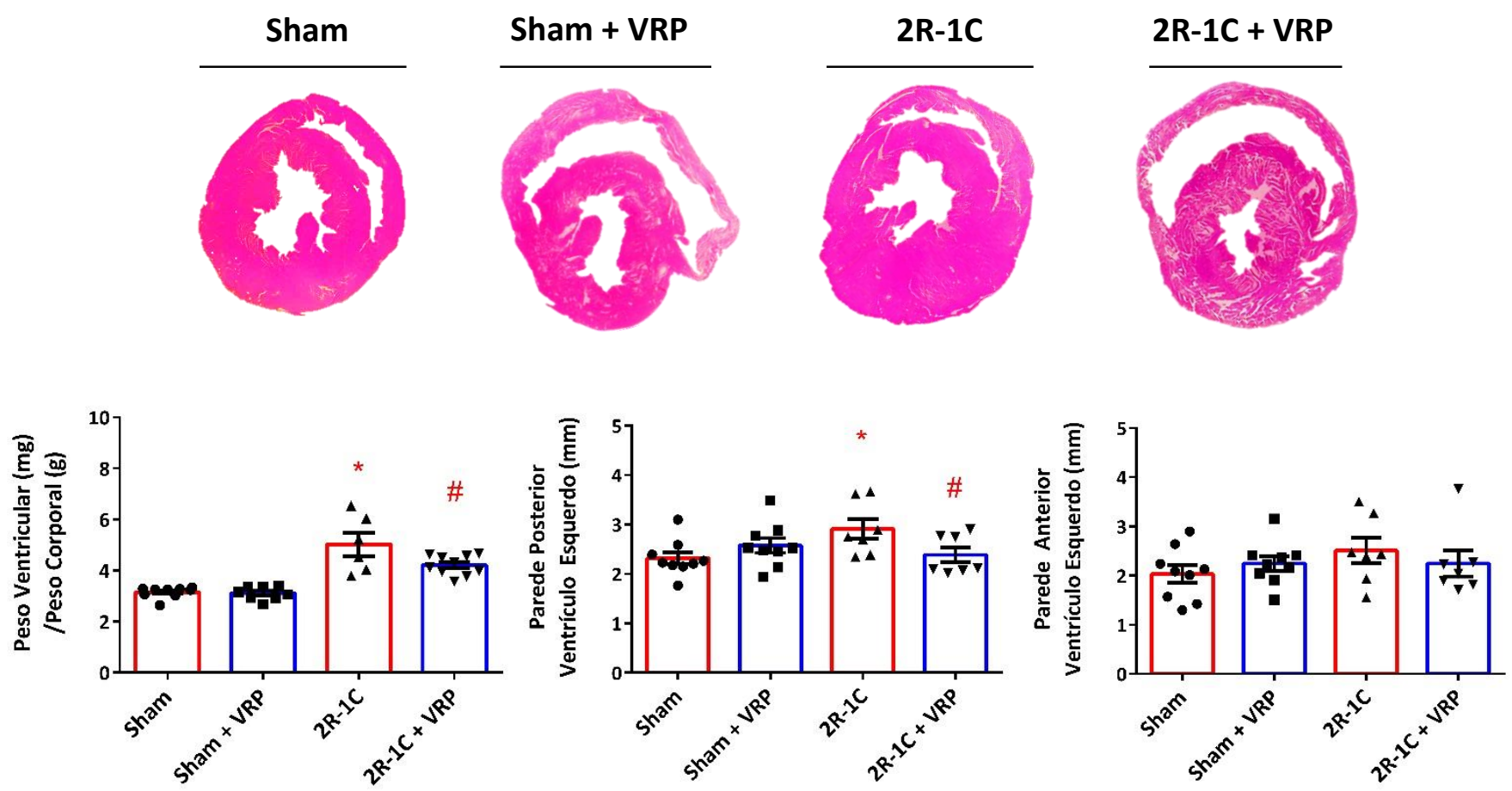

Figura 6: Avaliação morfológica por histologia corada com hematoxilina-eosina dos corações dos animais submetidos à hipertensão renovascular por dez semanas e tratamento com cloridrato de verapamil $(8 \mathrm{mg} / \mathrm{kg} / \mathrm{bid})$ por gavagem. Os dados são apresentados como médias \pm EPM $\left(n=6-11\right.$ por grupo, ${ }^{*} p<0,05$ versus Sham e Sham + VRP; $\# p<0,05$ versus 2R-1C). Legenda: VRP: Verapamil. 

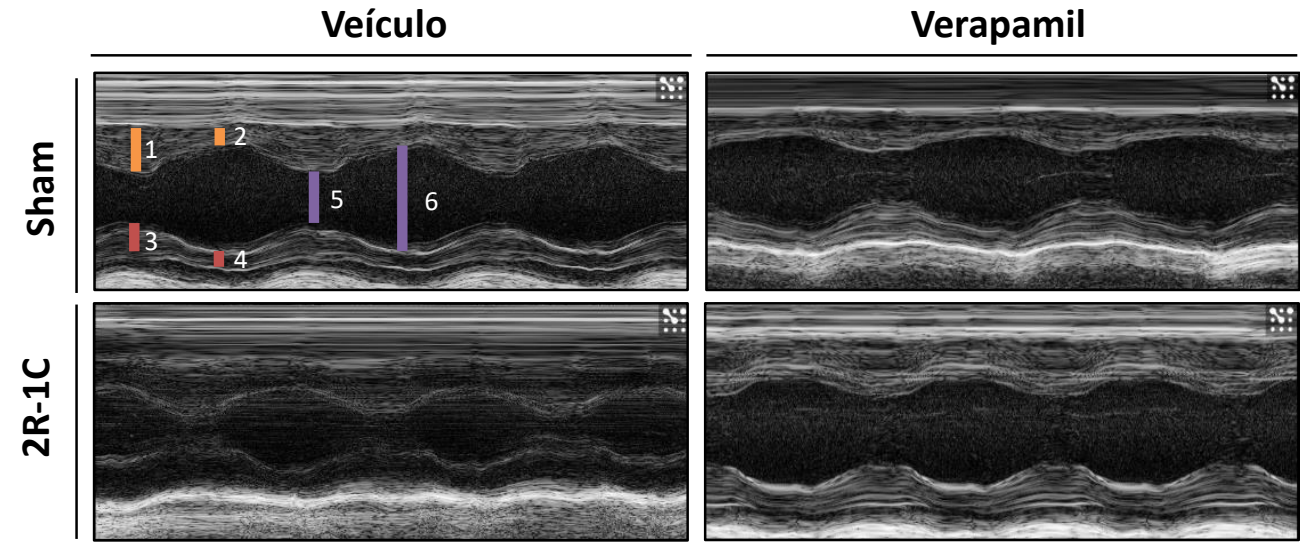

Diâmetro Interno Ventrículo Esquerdo (mm)
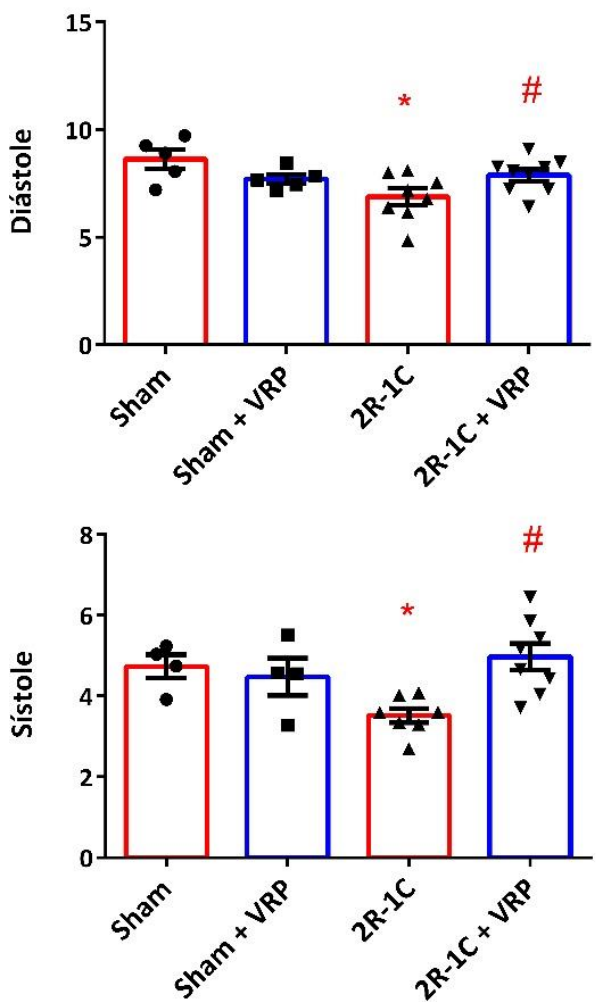

Parede Anterior Ventrículo Esquerdo ( $\mathrm{mm}$ )
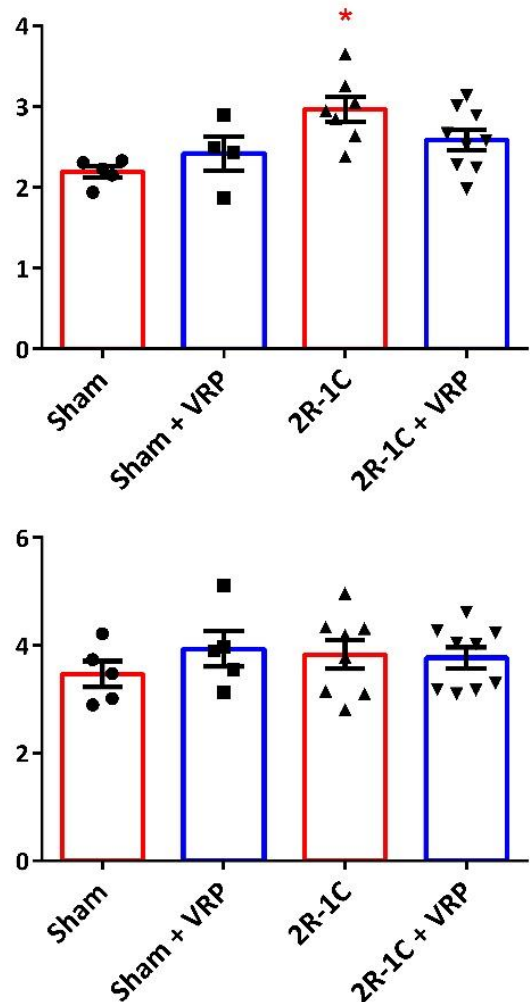

Parede Posterior Ventrículo Esquerdo (mm)

Figura 7: Avaliação morfológica por ecocardiograma dos corações dos animais submetidos à hipertensão renovascular por dez semanas e tratamento com cloridrato de verapamil $(8 \mathrm{mg} / \mathbf{k g} / \mathbf{b i d})$ por gavagem. Os dados são apresentados como médias \pm EPM ( $n=6-11$ por grupo, ${ }^{*} p<0,05$ versus Sham e Sham + VRP; $\# p<0,05$ versus $2 R-1 C$ ). Legenda: 1,2: parede anterior do ventrículo esquerdo durante a sístole e diástole, respectivamente; 3,4: parede posterior do ventrículo esquerdo durante a sístole e diástole, respectivamente; 5,6: câmara cardíaca esquerda durante a sístole e diástole, respectivamente. Legenda: VRP: Verapamil. 
Tabela 1: Parâmetros estruturais por ecocardiografia dos animais submetidos à hipertensão renovascular

\begin{tabular}{|c|c|c|c|c|}
\hline \multicolumn{2}{|c|}{ PARÂMETROS } & PAVE & PPVE & DIVE \\
\hline \multirow{4}{*}{ 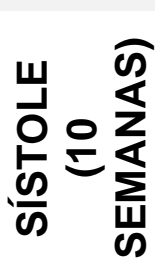 } & Sham & $3,46 \pm 0,24$ & $3,21 \pm 0,20$ & $4,73 \pm 0,29$ \\
\hline & Sham + VRP & $3,93 \pm 0,33$ & $3,66 \pm 0,18$ & $4,48 \pm 0,46$ \\
\hline & $2 R-1 C$ & $3,83 \pm 0,27$ & $4,07 \pm 0,16^{*}$ & $3,52 \pm 0,18^{*}$ \\
\hline & $2 R-1 C+V R P$ & $3,78 \pm 0,19$ & $3,21 \pm 0,15 \#$ & $4,97 \pm 0,33 \#$ \\
\hline \multirow{4}{*}{ 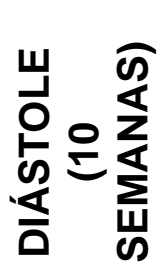 } & Sham & $2,19 \pm 0,07$ & $2,34 \pm 0,21$ & $8,63 \pm 0,45$ \\
\hline & Sham + VRP & $2,42 \pm 0,21$ & $2,86 \pm 0,22$ & $7,72 \pm 0,21$ \\
\hline & $2 R-1 C$ & $2,97 \pm 0,16^{*}$ & $3,13 \pm 0,18^{*}$ & $6,88 \pm 0,38^{*}$ \\
\hline & $2 R-1 C+V R P$ & $2,59 \pm 0,13$ & $2,32 \pm 0,14 \#$ & $7,89 \pm 0,27 \#$ \\
\hline
\end{tabular}

VRP: Verapamil; 2R-1C: 2 rins-1 clipe; PAVE: Parede Anterior do Ventrículo Esquerdo; PPVE: Parede Posterior do Ventrículo Esquerdo; DIVE: Diâmetro Interno do Ventrículo Esquerdo.

Tratamento com cloridrato de verapamil $(8 \mathrm{mg} / \mathrm{kg} / \mathrm{bid})$ por gavagem. Os valores são expressos em milímetros. Os dados são apresentados como médias \pm EPM ( $n=4-10$ por grupo, ${ }^{\star} p<0,05$ versus Sham e Sham + VRP; $\# p<0,05$ versus $2 R-1 C$ ). 


\subsection{Verapamil não altera a performance cardíaca na sobrecarga pressórica induzida por hipertensão renovascular}

A avaliação da função cardíaca in vivo por ecocardiografia demonstra que a função sistólica, observada pelos parâmetros fração de ejeção (que traduz a eficiência dos batimentos cardíacos) e a fração de encurtamento (que se baseia nos diâmetros transversais do ventrículo esquerdo obtidos ao final da diástole e da sístole) não apresentou diferença significativa entre os grupos. Isto sugere que o evento hipertrófico cardíaco resultou, neste caso, na manutenção da função ventricular nos ratos hipertensos. É interessante notar que o tratamento com o verapamil, mesmo sendo um bloequeador de canais para cálcio, não prejudicou a perfomance cardíaca nos ratos $2 \mathrm{R}-1 \mathrm{C}$ (Figura $8 \mathrm{~A})$.

A fim de avaliar a contratilidade intrínseca do músculo cardíaco, sem influências de cargas ou modulações neurohormonais, ao final de dez semanas de hipertensão renovascular, foi implementado o modelo de coração isolado originalmente proposto por Langendorff. A avaliação da pressão exercida pelo ventriculo esquerdo dos animais hipertensos $2 \mathrm{R}-1 \mathrm{C}$ em resposta ao estiramento crescente da parede cardíaca demonstra que esses corações apresentam um prejuízo significativo no estado contrátil quando comparados aos corações dos grupos controle. $\mathrm{O}$ tratamento com verapamil na dose de $8 \mathrm{mg} / \mathrm{kg} /$ bid parece não ter influência significativa sobre o estado contrátil intrínseco desses corações, embora apresentem uma disfunção cardíaca menos pronunciada (Figura 8B). 
A
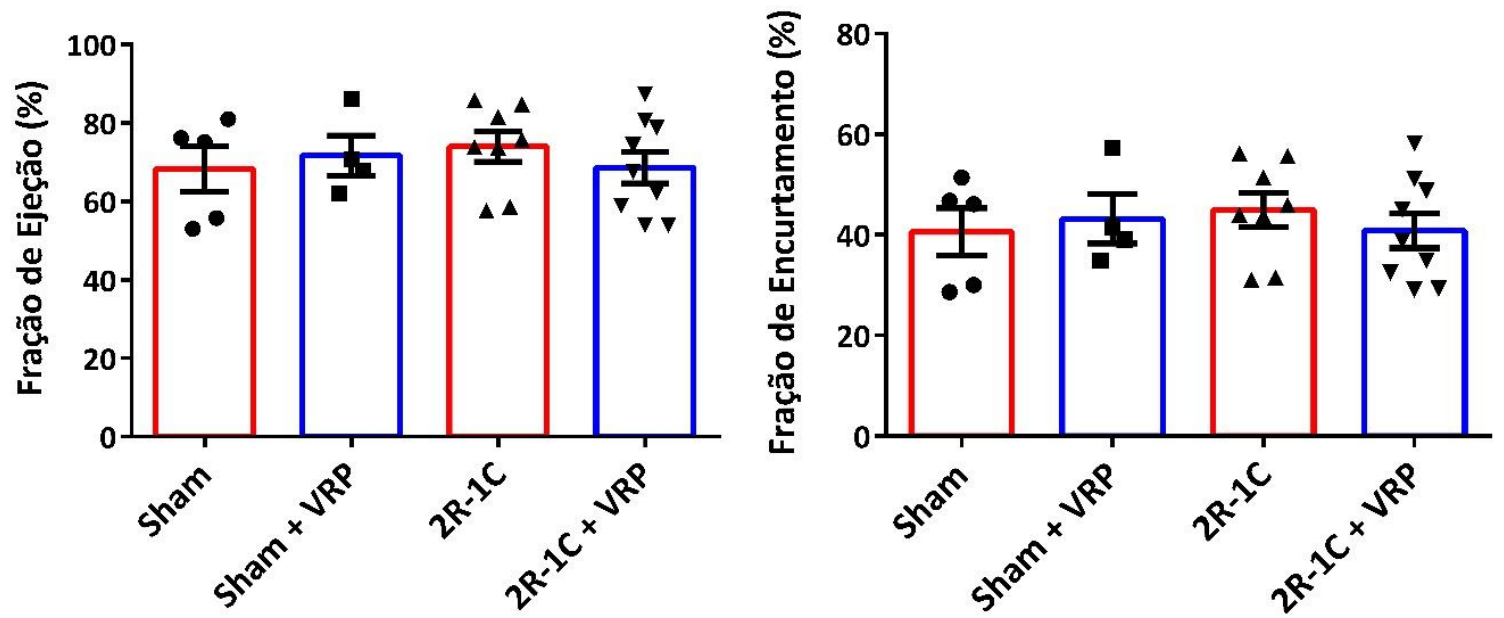

B

Pressão Desenvolvida / Peso Corporal (mmHg/g)

$\left.\begin{array}{c}50 \\ 40 \\ 30 \\ 20 \\ 10 \\ 0\end{array}\right]$

SHAM

SHAM + VRP

$2 \mathrm{R}-1 \mathrm{C}$

$2 R-1 C+V R P$
$+\mathrm{dP} / \mathrm{dt} /$ Peso Corporal $(\mathrm{mmHg} / \mathrm{s} / \mathrm{g})$
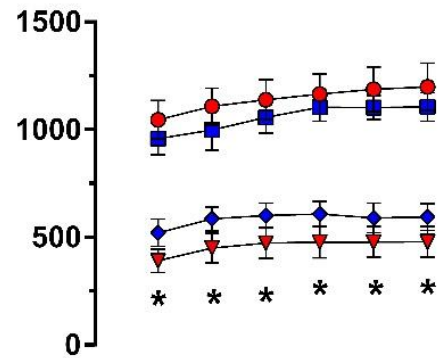

$\begin{array}{lccccc}2 & 10 & 20 & 30 & 40 & 50\end{array}$
-dP/dt / Peso Corporal $(\mathrm{mmHg} / \mathrm{s} / \mathrm{g})$

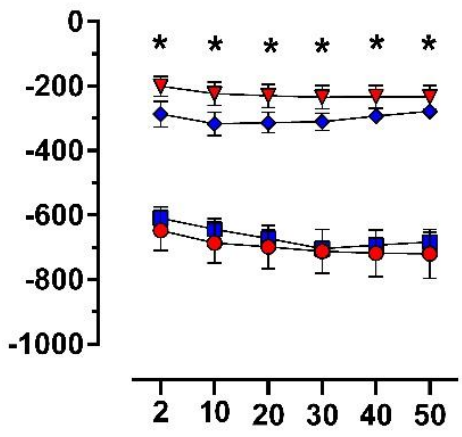

Pressão Diastólica do Ventrículo Esquerdo $(\mathrm{mmHg})$

Figura 8: Avaliação da função cardíaca in vivo por ecodopplercardiografia (A) e ex vivo pela metodologia de Langendorff (B) dos animais submetidos ao protocolo de hipertensão renovascular por dez semanas, tratamento com cloridrato de verapamil $(8 \mathrm{mg} / \mathrm{kg} / \mathrm{bid})$ por gavagem e respectivos controles. Os dados são apresentados como médias \pm EPM ( $n=4-10$ por grupo, ${ }^{*} p<0,05$ versus Sham e Sham + VRP). Legenda: VRP: Verapamil. 


\section{DISCUSSÃO}

Os achados apresentados nesse estudo demonstram uma participação do sistema proteolítico calpaína-1 no desenvolvimento e manutenção crônica da hipertrofia cardíaca induzida por sobrecarga pressórica. Os efeitos da calpaína-1 neste contexto podem estar relacionados à modulação da expressão protéica e atividade de MMP-2, cujos níveis se monstraram diminuídos com o tratamento com verapamil. Como demonstrado, a utilização do verapamil na dose de $8 \mathrm{mg} / \mathrm{kg} /$ bid não foi capaz de alterar significativamente a PAS, no entanto, os parâmetros cardíacos preditores de hipertrofia dos animais hipertensos tratados apresentaram níveis semelhantes aos controles. Este efeito é importante, embora não reduza significativamente a pressão arterial, pois contribui para a melhora das alterações cardíacas observadas na hipertensão arterial e favorece o não desenvolvimento de doenças cardiovasculares associadas.

Trabalhos anteriores demonstraram que a mesma dose de verapamil não se mostrou efetiva para a modulação hemodinâmica em modelo de insuficiência cardíaca induzida por infarto do miocárdio, sugerindo que os efeitos do bloqueador de canal para cálcio no remodelamento cardíaco foram independentes de influências hemodinâmicas (SANDMANN et al., 2001). Ademais, a utilização de verapamil em modelo de sepse severa in vitro e in vivo preveniram o aumento da ativação de calpaína-1, preservando a degradação de proteínas sarcoméricas, como a cadeia pesada de miosina e a actina sarcomérica, melhorando a função cardíaca e a sobrevida dos animais (CELES et al., 2013).

As calpaínas são cisteíno-proteases dependente de cálcio que têm papel fundamental no desenvolvimento de alterações mal adaptativas cardíacas 
(LETAVERNIER et al., 2012; PATTERSON et al., 2011; PERRIN; VERGELY; ROCHETTE, 2004; POTZ et al., 2016). A atividade aumentada de calpaína-1 contribui para a proteólise de alvos intracelulares, o que pode resultar em hipertrofia dos cardiomiócitos e consequente aumento da massa ventricular e disfunção cardíaca. Estudos demonstraram a participação da calpaína-1 no remodelamento cardíaco após indução de infarto e a superexpressão do inibidor endógeno, a calpastatina, foi capaz de atenuar as alterações desenvolvidas, como o aumento da área de secção transversal do cardiomiócito e a fibrose (LI et al., 2009). Calpaína-1 parece estar envolvida também na transição da hipertrofia cardíaca compensada para a insuficiência cardíaca e na cardiomiopatia induzida por doxorrubicina ao alterar os níveis proteicos de distrofina, uma proteína estrutural do cardiomiócito, contribuindo para a perda da função cardíaca (CAMPOS et al., 2011; PRADO et al., 2017). De fato, demonstramos que o aumento da PAS contribui para o aumento da expressão proteica e da atividade de calpaína-1 no ventrículo esquerdo dos animais submetidos ao modelo de hipertensão $2 \mathrm{R}-1 \mathrm{C}$ proposto por Goldblatt e que essas alterações a nível celular contribuem para o aumento da espessura da parede ventricular como observado.

As vias de ativação de genes pró-hipertróficos parecem ter uma contribuição da calpaína-1 em situações fisiopatológicas cardiovasculares. A ativação de calpaínas parece estar envolvida na disfunção cardíaca induzida por lipopolissacarídeo através da ativação da via IKBa/NF-KB, levando ao aumento da expressão proteica de TNF- $\alpha$ (Ll et al., 2014). Ademais, a atividade aumentada de calpaínas, em cardiomiócitos estimulados com angiotensina II, leva a proteólise do domínio autoinibitório da calcineurina A. A clivagem desse dominio contribui para a ativação constitutiva e translocação nuclear de CnA e NFATc4, mesmo após a remoção do estímulo 
hipertrófico. A calpaína contribui para a ativação da CnA também por meio da clivagem dos seus inibidores, a caína/cabina-1, em modelos in vitro de morte celular desencadeada por influxo de cálcio. A utilização de um inibidor de calpaína, a calpeptina, restaurou os níveis proteicos desses alvos. Essa interação entre o aumento da atividade de calpaína e a ativação de calcineurina parece estar relacionadas a diversas doenças cardio- e neurodegenerativas em que o cálcio tem um papel fundamental para a fisiopatologia (BURKARD et al., 2005; KIM et al., 2002; WU; TOMIZAWA; MATSUI, 2007).

A modulação da atividade e expressão de calpaína-1 em diferentes modelos de desenvolvimento de hipertrofia cardíaca levam à modulação na atividade de MMP2. Um estudo anterior demonstrou que a indução farmacológica e genética de diabetes tipo 1 leva ao aumento da atividade de calpaína-1 em coração de camundongos com concomitante aumento na atividade de MMP-2. Em contrapartida, a modulação da atividade de calpaína-1 através da superexpressão de calpastatina e em camundongos knock out para a subunidade reguladora de calpaína-1, a calpaína-4, diminuem a ativação de calpaína-1 e de MMP-2 com reversão da hipertrofia celular, deposição de colágeno e disfunção cardíaca. Esses dados sugerem uma interação entre os dois sistemas proteolíticos no desenvolvimento de hipertrofia cardíaca (LI et al., 2011).

MMP-2 é uma protease crítica que regula o remodelamento cardiovascular crônico decorrente da hipertensão arterial por meio da proteólise de alvos intracelulares ou extracelulares como os colágenos (CERON et al., 2013; RIZZI et al., 2013, 2014, 2010). A expressão gênica da MMP-2, um fator pró-hipertrófico já bem descrito, no contexto da hipertensão arterial e hipertrofia cardíaca, pode ser estimulada pelas vias já bem conhecidas de ativação de genes fetais comentadas 
anteriormente, como a via CnA/NFATc4 e IkBa/NF-KB (KANDASAMY et al., 2010; WU; SCHMID-SCHÖNBEIN, 2011) . A utilização de inibidores para NF-kB, como o ditiocarbamato de pirrolidina, modula a expressão proteica de MMP-2 no miocárdio e na vasculatura e melhora o remodelamento cardiovascular induzido por hipertensão renovascular (CAU et al., 2011, 2015). No nosso trabalho, demonstramos que a utlização do verapamil levou à diminuição da expressão proteica de MMP-2 e da atividade da isoforma de $64 \mathrm{kDa}$ da MMP-2 no ventrículo esquerdo dos animais hipertensos, sugerindo que esta enzima também pode estar relacionada às alterações morfofuncionais observadas.

Uma vez que o aumento da atividade de calpaína-1 favorece a ativação e translocação nuclear dos fatores de transcrição mencionados anteriormente e estas vias contribuem para o aumento da expressão proteica de MMP-2, podemos sugerir uma relação interdependente entre os dois sistemas enzimáticos no desenvolvimento da hipertrofia cardíaca induzida, nesse caso, pela hipertensão arterial. Por outro lado, outras vias também podem intercambiar a relação entre os dois sistemas: muitos elementos do citoesqueleto são alvos bem descritos para calpaínas, como a espectrina, a anquirina, a desmina e a vimentina. Esses elementos são fundamentais para a manutenção da integridade celular, disposição de organelas intracelulares e para o tráfego intracelular de vesículas. Produtos de proteólise da vimentina, por exemplo, favorecem o transporte de MMP-14, uma proteína relacionada ao aumento da migração celular e da ativação extracelular de MMP-2, mecanismo importante para proliferação de fibroblastos, remodelamento da matrix extracelular e fibrose na doença cardiovascular (BERK; FUJIWARA; LEHOUX, 2007; KANG et al., 2011; KWAK et al., 2012). Apesar de calpaínas e MMPs serem proteases importantes para a fisiopatologia de doenças cardiovasculares, pouco se sabe ainda se existe uma ação 
diferencial de atuação das enzimas ou se elas atuam de forma sinérgica para o desenvolvimento das alterações cardíacas observadas nessas doenças.

Geralmente assume-se que a hipertrofia cardíaca, nesse caso o remodelamento do ventrículo esquerdo, seja uma adaptação que se desenvolve quando uma carga de trabalho aumentada é cronicamente imposta ao miocárdio, que em resposta, hipertrofia para permitir a compensatória manutenção da função cardíaca. O desenvolvimento concêntrico da hipertrofia, nesse caso, normaliza a tensão sistólica, mantendo o consumo de oxigênio das fibras musculares e preservando a função sistólica (GROSSMAN; JONES; MCLAURIN, 1975). Frank e Starling demonstraram que, sob condições de pressão aórtica e volume constantes, o débito cardíaco ou a pressão desenvolvida pelo coração era uma função da pressão de enchimento venosa ou do volume diastólico final. Esses estudos, posteriormente, ficaram conhecidos como relação de Frank-Starling e se tornaram a base para o estudo da regulação do débito cardíaco e da contratilidade cardíaca intrínseca, que é definida como a qualidade do músculo cardíaco que determina o seu desempenho, independente das condições de carga (ALLEN; KENTISH, 1985; FRANK, 1959; PATTERSON; STARLING, 1914).

A avaliação dos corações demonstrou, neste trabalho, um aumento da massa cardíaca através da relação de peso do coração pelo peso corporal nos animais hipertensos quando comparados aos controles. Essa observação se deve ao aumento da espessura da parede posterior do ventrículo esquerdo desses animais a partir da avaliação por histomorfometria, que foi confirmada por ecocardiografia. A câmara esquerda, em consequência ao espessamento da parede ventricular, apresentou-se diminuída. O tratamento com verapamil preveniu as alterações morfológicas encontradas nos animais hipertrofiados. A avaliação da função cardíaca por 
ecocardiografia demonstrou a preservação da função sistólica avaliada a partir dos parâmetros fração de ejeção e fração de encurtamento. Apesar do seu efeito conhecidamente inotrópico negativo, o verapamil não foi capaz de modificar a função sistólica a partir da avaliação desses parâmetros.

No entanto, ao avaliarmos a contratilidade intrínseca do músculo cardíaco, pela metodologia de coração isolado de Langendorff, pudemos perceber uma disfunção pronunciada nos corações dos animais hipertensos quando mensurados os índices de contratilidade e pressão desenvolvida ex vivo em comparação aos animais controle. O tratamento com verapamil parece não apresentar influência significativa sobre o estado contrátil intrínseco desses corações, embora apresentem uma melhora das alterações morfológicas. Um experimento semelhante foi realizado por Shimamatsu e Fouad-Tarazi (1986): a uma dada pressão de perfusão constante, os animais submetidos ao modelo de hipertensão renovascular apresentaram um prejuízo significativo no estado inotrópico dado pela dP/dt máxima ventricular e na pressão ventricular desenvolvida quando comparados aos controles (SHIMAMATSU; FOUAD-TARAZI, 1986).

Esses dados parecem indicar uma participação dos sistemas de compensação in vivo, tais como o sistema nervoso autônomo e os sistemas humorais, que modulam as variações na pós-carga, pré-carga, reserva de fluxo coronariano e contratilidade intrínseca do coração, visto que na situação ex vivo, onde essas influências são controladas, pudemos observar ao final de 10 semanas de hipertensão a disfunção cardíaca nos animais hipertensos. Diante das considerações, o mecanismo proposto precisa ser melhor investigado. 


\section{CONCLUSÃO}

Os resultados aqui apresentados indicam um envolvimento dos sistemas proteolítcos calpaína-1 e MMP-2 no desenvolvimento da hipertrofia cardíaca induzida por hipertensão renovascular. Ademais, a utilização do bloqueador para canal de cálcio verapamil, em sua dose inefetiva para a diminuição da pressão arterial sistólica, foi capaz de prevenir as alterações características do remodelamento hipertrófico concêntrico cardíaco ao diminuir a expressão de calpaína-1 e MMP-2 e a ativação extracelular de MMP-2, dada pela atividade da isoforma de 64kDa desta enzima. 


\section{REFERÊNCIAS}

AKERS, W. S. et al. Renin-angiotensin system and sympathetic nervous system in cardiac pressure-overload hypertrophy. Am J Physiol Heart Circ Physiol, [s. I.], 2000.

ALI, Mohammad A. M. et al. Titin is a target of matrix metalloproteinase-2: Implications in myocardial ischemia/reperfusion injury. Circulation, [s. I.], 2010.

ALI, Mohammad A. M. et al. Calpain inhibitors exhibit matrix metalloproteinase-2 inhibitory activity. Biochemical and Biophysical Research Communications, [s. I.], 2012.

ALLEN, D. G.; KENTISH, J. C. The cellular basis of the length-tension relation in cardiac muscle. Journal of Molecular and Cellular Cardiology, 1985.

BARKI-HARRINGTON, Liza; PERRINO, Cinzia; ROCKMAN, Howard A. Network integration of the adrenergic system in cardiac hypertrophy. Cardiovascular Research, 2004.

BELL, Robert M.; MOCANU, Mihaela M.; YELLON, Derek M. Retrograde heart perfusion: The Langendorff technique of isolated heart perfusion. Journal of Molecular and Cellular Cardiology, 2011.

BELO, V. A.; GUIMARÃES, Danielle A.; CASTRO, Michele Mazzaron. Matrix Metalloproteinase 2 as a Potential Mediator of Vascular Smooth Muscle Cell Migration and Chronic Vascular Remodeling in Hypertension. Journal of vascular research, [s. I.], v. 52, n. 4, p. 221-31, 2015.

BELO, Vanessa de Almeida et al. Matrix metalloproteinase (MMP)-2 decreases calponin-1 levels and contributes to arterial remodeling in early hypertension. Biochemical Pharmacology, [s. I.], 2016.

BERGMAN, M. R. et al. Cardiac matrix metalloproteinase-2 expression independently induces marked ventricular remodeling and systolic dysfunction. AJP: Heart and Circulatory Physiology, [s. I.], 2006.

BERK, Bradford C.; FUJIWARA, Keigi; LEHOUX, Stephanie. ECM remodeling in hypertensive heart disease. Journal of Clinical Investigation, 2007.

BERNARDO, M. Margarida; FRIDMAN, Rafael. TIMP-2 (tissue inhibitor of metalloproteinase-2) regulates MMP-2 (matrix metalloproteinase-2) activity in the extracellular environment after pro-MMP-2 activation by MT1 (membrane type 1)-MMP. The Biochemical journal, [s. I.], 2003.

BERRIDGE, Michael J.; BOOTMAN, Martin D.; RODERICK, H. Llewelyn.Calcium signaling: dynamics, homeostasis and remodeling. Nature Reviews: Molecular Cell Biology. [s. I.], v. 4, n. July, 2003. 
BLOOM, Michelle W. et al. Heart failure with reduced ejection fraction. Nature Reviews Disease Primers, [s. I.], 2017.

BRADFORD, Marion M. A rapid and sensitive method for the quantitation of microgram quantities of protein utilizing the principle of protein-dye binding. Analytical Biochemistry, [s. I.], 1976.

BURKARD, Natalie et al. Targeted proteolysis sustains calcineurin activation. Circulation, [s. I.], v. 111, n. 8, p. 1045-1053, 2005.

CAMPOS, Erica C. et al. Calpain-mediated dystrophin disruption may be a potential structural culprit behind chronic doxorubicin-induced cardiomyopathy. European Journal of Pharmacology, [s. I.], v. 670, n. 2-3, p. 541-553, 2011.

CAU, S. B. A. et al. Pyrrolidine dithiocarbamate down-regulates vascular matrix metalloproteinases and ameliorates vascular dysfunction and remodelling in renovascular hypertension. British Journal of Pharmacology, [s. I.], v. 164, n. 2, p. 372-381, 2011.

CAU, Stefany B. A. et al. The Nuclear Factor kappaB Inhibitor Pyrrolidine Dithiocarbamate Prevents Cardiac Remodelling and Matrix Metalloproteinase2 Up-Regulation in Renovascular Hypertension. Basic and Clinical Pharmacology and Toxicology, [s. I.], v. 117, n. 4, p. 234-241, 2015.

CELES, Mara R. N. et al. Disruption of Calcium Homeostasis in Cardiomyocytes Underlies Cardiac Structural and Functional Changes in Severe Sepsis. PLoS ONE, [s. I.], v. 8, n. 7, 2013.

CERON, Carla S. et al. Nebivolol attenuates prooxidant and profibrotic mechanisms involving TGF- $\beta$ and MMPs, and decreases vascular remodeling in renovascular hypertension. Free Radical Biology and Medicine, [s. I.], v. 65, p. 47-56, 2013.

CROALL, Dorothy E.; MOFFETT, Katherin; HATCH, Harold. Casein zymography of calpains using a 4-(2- hydroxyethyl)-1-piperazineethanesulfonic acid-imidazole buffer. Analytical Biochemistry, [s. I.], v. 304, n. 1, p. 129-132, 2002.

DE JONGH, Karen S. et al. Differential proteolysis of the full-length form of the L-type calcium channel alpha 1 subunit by calpain. Journal of Neurochemistry, [s. I.], v. 63 , n. 4, p. 1558-1564, 1994.

DORN, Gerald W.; ROBBINS, Jeffrey; SUGDEN, Peter H. Phenotyping hypertrophy: Eschew obfuscation. Circulation Research, [s. I.], 2003.

DOSTAL, D. E.; BAKER, K. M. The cardiac renin-angiotensin system: Conceptual, or a regulator of cardiac function? Circulation Research, [s. I.], 1999.

FRANK, Otto. On the dynamics of cardiac muscle. American Heart Journal, [s. I.], 1959. 
FREY, Norbert et al. Hypertrophy of the Heart: A New Therapeutic Target?. Circulation, 2004.

GLADING, Angela; LAUFFENBURGER, Douglas A.; WELLS, Alan. Cutting to the chase: Calpain proteases in cell motility. Trends in Cell Biology, 2002.

GOLDBLATT, H. Experimental Renal Hypertension: Mechanism of Production and Maintenance. Circulation, [s. I.], 1958.

GROSSMAN, W.; JONES, D.; MCLAURIN, L. P. Wall stress and patterns of hypertrophy in the human left ventricle. The Journal of clinical investigation, [s. I.], v. 56, n. 1, p. 56-64, 1975.

JIANG, Liqun et al. Increased aortic calpain-1 activity mediates age-associated angiotensin II signaling of vascular smooth muscle cells. PLoS ONE, [s. I.], v. 3, n. 5, 2008.

JIANG, Liqun et al. Calpain-1 regulation of matrix metalloproteinase 2 activity in vascular smooth muscle cells facilitates age-associated aortic wall calcification and fibrosis. Hypertension, [s. I.], v. 60, n. 5, p. 1192-1199, 2012.

KANDASAMY, Arulmozhi D. et al. Matrix metalloproteinase-2 and myocardial oxidative stress injury: Beyond the matrix. Cardiovascular Research, 2010.

KANG, Hojin et al. Fluid shear stress and sphingosine 1-phosphate activate calpain to promote Membrane Type 1 Matrix Metalloproteinase (MT1-MMP) membrane translocation and endothelial invasion into three-dimensional collagen matrices. Journal of Biological Chemistry, [s. I.], 2011.

KIM, Min-Jung et al. Calpain-dependent cleavage of cain/cabin1 activates calcineurin to mediate calcium-triggered cell death. Proceedings of the National Academy of Sciences of the United States of America, [s. I.], v. 99, n. 15, p. 9870-5, 2002.

KWAK, Hyeong II et al. Calpain-mediated vimentin cleavage occurs upstream of MT1MMP membrane translocation to facilitate endothelial sprout initiation. Angiogenesis, [s. I.], 2012.

LETAVERNIER, Emmanuel et al. Targeting the calpain/calpastatin system as a new strategy to prevent cardiovascular remodeling in angiotensin II-induced hypertension. Circulation Research, [s. I.], v. 102, n. 6, p. 720-728, 2008.

LETAVERNIER, Emmanuel et al. The role of calpains in myocardial remodelling and heart failure. Cardiovascular Research, 2012.

LI, Xiaoping et al. Over-expression of calpastatin inhibits calpain activation and attenuates myocardial dysfunction during endotoxaemia. Cardiovascular Research, [s. I.], v. 83, n. 1, p. 72-79, 2009.

$\mathrm{LI}$, Xiaoping et al. Cleavage of IKBa by calpain induces myocardial NF-kB activation, 
TNF- $\alpha$ expression, and cardiac dysfunction in septic mice. Am J Physiol Heart Circ Physiol, [s. I.], v. 306, n. 6, p. H833-H843, 2014.

LI, Ying et al. Targeted inhibition of calpain reduces myocardial hypertrophy and fibrosis in mouse models of type 1 diabetes. Diabetes, [s. I.], 2011.

LIU, Rui et al. Effect of protein S-nitrosylation on autolysis and catalytic ability of $\mu$ calpain. Food Chemistry, [s. I.], 2016.

LU, Pengfei et al. Extracellular Matrix degradation and remodeling in development and disease. Cold Spring Harbor Perspectives in Biology, [s. I.], 2011.

MA, Wanli et al. Calpain mediates pulmonary vascular remodeling in rodent models of pulmonary hypertension, and its inhibition attenuates pathologic features of disease. Journal of Clinical Investigation, [s. I.], 2011.

NAKAZAWA, Mitsuru. Effects of Calcium lon, Calpains, and Calcium Channel Blockers on Retinitis Pigmentosa. Journal of Ophthalmology, [s. I.], 2011.

NISHIDA, Kazuhiko; YAMAGUCHI, Osamu; OTSU, Kinya. Degradation systems in heart failure. Journal of Molecular and Cellular Cardiology, 2015.

NOBRE, Fernando et al. VI Diretrizes Brasileiras. VI Diretrizes Brasileiras de Hipertensão - Sociedade Brasileira de Cardiologia, [s. I.], 2010.

PARENTE, Juliana M. et al. Matrix Metalloproteinase-2 Activity is Associated with Divergent Regulation of Calponin-1 in Conductance and Resistance Arteries in Hypertension-induced Early Vascular Dysfunction and Remodelling. Basic and Clinical Pharmacology and Toxicology, [s. I.], 2017.

PATTERSON, Cam et al. Tear me down: Role of calpain in the development of cardiac ventricular hypertrophy. Circulation Research, 2011.

PATTERSON, S. W.; STARLING, E. H. On the mechanical factors which determine the output of the ventricles. The Journal of Physiology, [s. I.], 1914.

PERRIN, C.; VERGELY, C.; ROCHETTE, L. Les calpaïnes : Implication en pathologie cardiaque. Annales de Cardiologie et d'Angeiologie, 2004.

POSTOVIT, Lynne Marie et al. Calpain is required for MMP-2 and U-PA expression in SV40 large T-antigen-immortalized cells. Biochemical and Biophysical Research Communications, [s. I.], 2002.

POTZ, Brittany A. et al. Calpains and Coronary Vascular Disease. Circulation Journal, [s. I.], v. 80, n. 1, p. 4-10, 2016.

PRADO, Fernanda P. et al. Early dystrophin loss is coincident with the transition of compensated cardiac hypertrophy to heart failure. PLoS ONE, [s. I.], v. 12, n. 12, 2017. 
REDFIELD, Margaret M. Heart Failure with Preserved Ejection Fraction. New England Journal of Medicine, [s. I.], 2016.

RIZZI, Elen et al. Temporal changes in cardiac matrix metalloproteinase activity, oxidative stress, and TGF- $\beta$ in renovascular hypertension-induced cardiac hypertrophy. Experimental and Molecular Pathology, [s. I.], v. 94, n. 1, p. 19, 2013.

RIZZI, Elen et al. 1-Adrenergic blockers exert antioxidant effects, reduce matrix metalloproteinase activity, and improve renovascular hypertension-induced cardiac hypertrophy. Free Radical Biology and Medicine, [s. I.], v. 73, p. 308317, 2014.

RIZZI, Élen et al. Matrix Metalloproteinase Inhibition Improves Cardiac Dysfunction and Remodeling in 2-Kidney, 1-Clip Hypertension. Journal of Cardiac Failure, [s. I.], v. 16, n. 7, p. 599-608, 2010.

SANDMANN, S. et al. Calcium channel blockade limits cardiac remodeling and improves cardiac function in myocardial infarction-induced heart failure in rats. Journal of cardiovascular pharmacology, [s. I.], v. 37, p. 64-77, 2001.

SCHÖN, Christian; PAQUET-DURAND, François; MICHALAKIS, Stylianos. Cav1.4 Ltype calcium channels contribute to calpain activation in degenerating photoreceptors of rd1 mice. PLoS ONE, [s. I.], 2016.

SCHULZ, Richard. Intracellular Targets of Matrix Metalloproteinase-2 in Cardiac Disease: Rationale and Therapeutic Approaches. Annual Review of Pharmacology and Toxicology, [s. I.], 2007.

SELVETELLA, Giulio; LEMBO, Giuseppe. Mechanisms of Cardiac HypertrophyHeart Failure Clinics, 2005.

SHIMAMATSU, Kazumasa; FOUAD-TARAZI, Fetnat M. Basal inotropic state in rats with renal hypertension: influence of coronary flow and perfusion pressure. Cardiovascular Research. [s. I.], p. 269-274, 1986.

SINGH, Raja B. et al. Activation of proteolytic enzymes and depression of the sarcolemmal $\mathrm{Na}+\mathrm{K}+$-ATPase in ischemia-reperfused heart may be mediated through oxidative stress. Canadian journal of physiology and pharmacology, [s. I.], 2012.

STORR, Sarah J. et al. The calpain system and cancer. Nature Reviews Cancer, 2011.

TE RIET, Luuk et al. Hypertension: Renin-Angiotensin-Aldosterone System Alterations. Circulation Research, 2015.

VISSE, Robert; NAGASE, Hideaki. Matrix metalloproteinases and tissue inhibitors of metalloproteinases: Structure, function, and biochemistry. Circulation Research, 2003. 
WANG, Wenjie et al. Intracellular action of matrix metalloproteinase-2 accounts for acute myocardial ischemia and reperfusion injury. Circulation, [s. I.], 2002.

WANICHAWAN, Pimthanya et al. Molecular basis of Calpain cleavage and inactivation of the sodium-calcium exchanger 1 in heart failure. Journal of Biological Chemistry, [s. I.], v. 289, n. 49, p. 33984-33998, 2014.

WEBER, K. T.; BRILLA, C. G. Pathological hypertrophy and cardiac interstitium: Fibrosis and renin-angiotensin-aldosterone system. Circulation, 1991.

WILLIAMS, Andrea et al. Novel targets for Huntington's disease in an mTORindependent autophagy pathway. Nature Chemical Biology, [s. I.], 2008.

WU, Hai Yan; TOMIZAWA, Kazuhito; MATSUI, Hideki. Calpain-calcineurin signaling in the pathogenesis of calcium-dependent disorder. Acta Medica Okayama, 2007.

WU, Kwan-I. Sharon; SCHMID-SCHÖNBEIN, Geert W. Nuclear factor kappa B and matrix metalloproteinase induced receptor cleavage in the spontaneously hypertensive rat. Hypertension, [s. I.], v. 57, p. 261-268, 2011.

ZILE, Michael R. et al. Mechanistic relationship between membrane type-1 matrix metalloproteinase and the myocardial response to pressure overload. Circulation: Heart Failure, [s. I.], v. 7, n. 2, p. 340-350, 2014. 